\title{
Article
}

\section{Transcriptome Analysis Unravels Key Factors Involved in Response to Potassium Deficiency and Feedback Regulation of $\mathrm{K}^{+}$Uptake in Cotton Roots}

\author{
Doudou Yang ${ }^{1,2}$, Fangjun $\mathrm{Li}^{2}$, Fei $\mathrm{Yi}^{2}{ }^{2}$ A. Egrinya Eneji ${ }^{3}$, Xiaoli Tian ${ }^{1,2, *}$ and Zhaohu Li ${ }^{1,2}$ \\ 1 State Key Laboratory of Plant Physiology and Biochemistry, China Agricultural University, \\ Beijing 100193, China; yddwx1991520@163.com (D.Y.); lizhaohu@cau.edu.cn (Z.L.) \\ 2 College of Agronomy and Biotechnology, China Agricultural University, Beijing 100193, China; \\ lifangjun@cau.edu.cn (F.L.); yifei56@cau.edu.cn (F.Y.); \\ 3 Department of Soil Science, Faculty of Agriculture, Forestry and Wildlife Resources Management, \\ University of Calabar, Calabar 540271, Nigeria; aeeneji@yahoo.co.uk \\ * Correspondence: tianxl@cau.edu.cn
}

check for updates

Citation: Yang, D.; Li, F.; Yi, F.; Eneji, A.E.; Tian, X.; Li, Z. Transcriptome Analysis Unravels Key Factors Involved in Response to Potassium Deficiency and Feedback Regulation of $\mathrm{K}^{+}$Uptake in Cotton Roots. Int. J. Mol. Sci. 2021, 22, 3133. https:// doi.org/10.3390/ijms22063133

Academic Editors: Giampiero Cai, Luigi Parrotta and Lavinia Mareri

Received: 1 March 2021

Accepted: 16 March 2021

Published: 19 March 2021

Publisher's Note: MDPI stays neutral with regard to jurisdictional claims in published maps and institutional affiliations.

Copyright: (c) 2021 by the authors. Licensee MDPI, Basel, Switzerland. This article is an open access article distributed under the terms and conditions of the Creative Commons Attribution (CC BY) license (https:/ / creativecommons.org/licenses/by/ $4.0 /)$.

\begin{abstract}
To properly understand cotton responses to potassium $\left(\mathrm{K}^{+}\right)$deficiency and how its shoot feedback regulates $\mathrm{K}^{+}$uptake and root growth, we analyzed the changes in root transcriptome induced by low $\mathrm{K}^{+}\left(0.03 \mathrm{mM} \mathrm{K} \mathrm{K}^{+}\right.$, lasting three days $)$in self-grafts of a $\mathrm{K}^{+}$inefficient cotton variety (CCRI41/CCRI41, scion/rootstock) and its reciprocal grafts with a $\mathrm{K}^{+}$efficient variety (SCRC22/CCRI41). Compared with CCRI41/CCRI41, the SCRC22 scion enhanced the $\mathrm{K}^{+}$uptake and root growth of CCRI41 rootstock. A total of 1968 and 2539 differently expressed genes (DEGs) were identified in the roots of CCRI41/CCRI41 and SCRC22/CCRI41 in response to $\mathrm{K}^{+}$deficiency, respectively. The overlapped and similarly (both up- or both down-) regulated DEGs in the two grafts were considered the basic response to $\mathrm{K}^{+}$deficiency in cotton roots, whereas the DEGs only found in SCRC22/CCRI41 (1954) and those oppositely (one up- and the other down-) regulated in the two grafts might be the key factors involved in the feedback regulation of $\mathrm{K}^{+}$uptake and root growth. The expression level of four putative $\mathrm{K}^{+}$transporter genes (three GhHAK5s and one GhKUP3) increased in both grafts under low $\mathrm{K}^{+}$, which could enable plants to cope with $\mathrm{K}^{+}$deficiency. In addition, two ethylene response factors (ERFs), GhERF15 and GhESE3, both down-regulated in the roots of CCRI41/CCRI41 and SCRC22/CCRI41, may negatively regulate $\mathrm{K}^{+}$uptake in cotton roots due to higher net $\mathrm{K}^{+}$uptake rate in their virus-induced gene silencing (VIGS) plants. In terms of feedback regulation of $\mathrm{K}^{+}$uptake and root growth, several up-regulated DEGs related to $\mathrm{Ca}^{2+}$ binding and CIPK (CBL-interacting protein kinases), one up-regulated GhKUP3 and several up-regulated GhNRT2.1s probably play important roles. In conclusion, these results provide a deeper insight into the molecular mechanisms involved in basic response to low $\mathrm{K}^{+}$stress in cotton roots and feedback regulation of $\mathrm{K}^{+}$uptake, and present several low $\mathrm{K}^{+}$tolerance-associated genes that need to be further identified and characterized.
\end{abstract}

Keywords: cotton; grafting; potassium deficiency; nutrient transporter; transcription factor

\section{Introduction}

Potassium $\left(\mathrm{K}^{+}\right)$is an essential macronutrient that plays crucial roles in plant growth, development, and response to stress, which include balancing the electrical charge of membranes, activating enzymes, transporting of minerals and metabolites, turgor regulation, osmoregulation, as well as signal transduction [1,2]. Potassium starvation can inhibit plant photosynthesis, reduce transpiration rate and stomatal conductance, affect carbohydrate translocation and metabolism, weaken resistance to biological and abiotic stresses, and consequently decrease crop yield and quality [1,3]. Cotton (Gossypium hirsutum L.) is a potassium-sensitive crop due to its sparse roots and its relatively inefficient $\mathrm{K}^{+}$absorp- 
tion [3]. However, $\mathrm{K}^{+}$availability in the soil is often limited which causes low- $\mathrm{K}^{+}$stress during cotton growth periods [2,3].

The $\mathrm{K}^{+}$uptake in plant roots involves diverse $\mathrm{K}^{+}$channels and transporters. Plant $\mathrm{K}^{+}$channels consist of members of the Shaker, tandem-pore (TPK), and two-pore channel (TPC) families, and $\mathrm{K}^{+}$transporters include members of the KUP/HAK/KT, high-affinity $\mathrm{K}^{+}$transporter (HKT), and cation-proton antiporter (CPA) families [4,5]. Under high external $\mathrm{K}^{+}$concentrations $(>0.3 \mathrm{mM}), \mathrm{K}^{+}$channels mainly mediate low-affinity $\mathrm{K}^{+}$uptake, whereas $\mathrm{K}^{+}$transporters mainly mediate high-affinity $\mathrm{K}^{+}$uptake under low external $\mathrm{K}^{+}$ concentrations $(<0.2 \mathrm{mM})$ [4].

Plants have evolved complex signaling pathways to address the issue of fluctuating external $\mathrm{K}^{+}$levels. Root cells could perceive external $\mathrm{K}^{+}$deficiency and generate initial $\mathrm{K}^{+}$signaling, and this $\mathrm{K}^{+}$signaling is subsequently transduced or encoded by $\mathrm{Ca}^{2+}$ and reactive oxygen species (ROS) sensors, which then induce changes in signaling components, including phytohormones and transcription factors (TFs). Phytohormones and TFs then regulate the downstream (including $\mathrm{K}^{+}$channels and transporters) transcriptional, translational, and posttranslational responses, and finally, plants exert many morphological and physiological adaptive changes that assist survival under $\mathrm{K}^{+}$-deficiency stress [5-7].

In higher plants, there are several types of " $\mathrm{Ca}^{2+}$ sensors" that decode $\mathrm{Ca}^{2+}$ at different levels in the cell [8]. For instance, calmodulin (CaM) and calmodulin-like (CML) can regulate functions of TFs. CaM binding proteins can bind to $\mathrm{CaM}$ in a $\mathrm{Ca}^{2+}$-dependent and reversible manner. Calcineurin B-like (CBL) protein is without enzymatic activity per se, but interacts with specific CBL-interacting protein kinases (CIPKs) to phosphorylate target proteins [9]. Calcium-dependent protein kinases (CDPKs or CPKs) have the unique feature of a catalytic protein kinase domain and a regulatory domain [10]. At the cellular level, $\mathrm{K}^{+}$deficiency has been shown to elevate $\left[\mathrm{Ca}^{2+}\right]_{\text {cyt }}$ that activates downstream signalling through CBL-CIPK complexes [11]. The CBL1/CBL9-CIPK23 complex can activate both $\mathrm{K}^{+}$channel AKT1 [12] and $\mathrm{K}^{+}$transporter HAK5 through phosphorylation to enhance $\mathrm{K}^{+}$ uptake [13]. Another $\mathrm{K}^{+}$channel AKT2 mediates $\mathrm{K}^{+}$transport in the phloem and regulates sucrose loading [14]. Its translocation from endoplasmic reticulum (ER) membrane to the plasma membrane (PM) is $\mathrm{Ca}^{2+}$-dependent and regulated by the CBL4 together with the CIPK6 in Arabidopsis [15].

Nicotinamide adenine dinucleotide phosphate (NADPH) oxidase, encoded by Respiratory burst oxidase homologue (Rboh) gene, is the main source of ROS production induced by stress (including low- $\mathrm{K}^{+}$stress) [16]. Also, other oxidases and peroxidases are involved in ROS production in response to $\mathrm{K}^{+}$deficiency [5]. To alleviate the damage caused by oxidative stress, plants have developed effective enzymatic defense system such as peroxidase (POD), glutathione S-transferase (GST), superoxide dismutase (SOD), peroxiredoxin (PRX), glutaredoxin (GRX), catalase (CAT), and ascorbate peroxidase (APX) [17], as well as non-enzymatic antioxidants, including glutathione (GSH), and ascorbate (AsA) [18].

There are evidences that $\mathrm{K}^{+}$transporters from the KT/KUP/HAK family, may function as auxin carriers or are involved in auxin signaling. The alteration of root growth and development of $\mathrm{K}^{+}$-deprived plants was linked to decreased auxin concentrations and disruption of auxin distribution [19-23]. Potassium deprivation decreased cytokinin (CTK) level, which allows fast and effective stimulation of ROS accumulation, root hair growth and $H A K 5$ expression, leading to plant adaptation to low $\mathrm{K}^{+}$conditions [24]. In contrast to CTK, the content of abscissic acid (ABA) increased under $\mathrm{K}^{+}$deficiency [25], and the putative components of ABA signaling pathway may regulate the activity of $\mathrm{K}^{+}$channels or transporters via phosphorylation / dephosphorylation. For example, the $\mathrm{C}$ terminal cytosolic region of $\mathrm{K}^{+}$transporters KUP6 can be phosphorylated by the SNF1-related protein kinases 2E (SRK2E) [21]. In addition, the $\mathrm{K}^{+}$channel AKT1 can be dephosphorylated by AKT1-interacting PP2C1 (AIP1) [26-28] or be inactivated by PP2CA through inhibiting the kinase activity of CIPK6 [12]. Ethylene signaling is a component of the plant's response to low $\mathrm{K}^{+}$that stimulates the production of ROS and induces the expression of highaffinity $\mathrm{K}^{+}$transporter HAK5 [29]. Ethylene signaling is also involved in the inhibition 
of lateral roots and improvement of root hair elongation in Arabidopsis under low $\mathrm{K}^{+}$ conditions $[29,30]$. Our previous work also showed that the cotton lateral root formation were significantly inhibited by low $\mathrm{K}^{+}$, which was accompanied by a strong increase (near six-fold) in ethylene release [19]. Furthermore, jasmonic acid (JA) participates in the response to $\mathrm{K}^{+}$deficiency in Arabidopsis [31], rice [32], and wheat [25], and may have putative roles in nutrient storage and remobilization as well as enhancing the defense potential of $\mathrm{K}^{+}$-deficient plants [31,33].

Previous reports showed that the genes encoding $\mathrm{K}^{+}$transporters, especially members of the KUP/HAK/KT family were mostly identified in response to $\mathrm{K}^{+}$deficiency or deprivation [34-37]. The HAK5 genes under $\mathrm{K}^{+}$deprivation were strongly induced in roots of Arabidopsis (AtHAK5) [38], pepper (CaHAK5) [39], tomato (LeHAK5) [40], and cotton (GhHAK5) [41]. However, the details of how HAK5 is regulated are still far from clear. Curently, only two TFs, AtRAP2.11 and AtARF2 that can bind to AtHAK5 promoter and positively or negatively regulate AtHAK5, have been conclusively identified [42,43].

In the last two decades, a number of authors have focused on low- $\mathrm{K}^{+}$stress using transcriptome, metabolome and proteomics analysis in model plants Arabidopsis and rice as well as other species [44-47]. However, there are no such reports on cotton yet to our knowledge. We once performed a reciprocal grafting using a $\mathrm{K}^{+}$inefficient cotton variety, CCRI41 and a $\mathrm{K}^{+}$efficient variety, SCRC22, and found that SCRC22 scion can feedback facilitate $\mathrm{K}^{+}$uptake in CCRI41 rootstock under $\mathrm{K}^{+}$deficiency [41]. Nevertheless, the underlying molecular mechanisms remain unclear. Here, we conducted a root transcriptome profiling of CCRI41/CCRI41 (scion/rootstock, self-grafts) and SCRC22/CCRI41 (reciprocal grafts) following three days of $\mathrm{K}^{+}$deficiency $\left(0.03 \mathrm{mM} \mathrm{K}^{+}\right)$. The genes that were similarly regulated in self- and reciprocal grafts were considered as the basic response to low $\mathrm{K}^{+}$conditions in cotton roots, and those only differently expressed in the roots of SCRC22/CCRI41 or oppositely regulated in CCRI41/CCRI41 and SCRC22/CCRI41 were regarded as specific response to low $\mathrm{K}^{+}$-stress in SCRC22/CCRI41, which would explain the feedback regulation of $\mathrm{K}^{+}$uptake and root growth in cotton.

\section{Results}

2.1. Effects of Low- $K^{+}$Stress on Phenotype, Chlorophyll Content, Biomass, and $\mathrm{K}^{+}$Content of CCRI41/CCRI41 and SCRC22/CCRI41

Grafting was performed hypocotyl-to-hypocotyl (Figure 1a) when the cotyledons of rootstock just fully expanded. The low- $\mathrm{K}^{+}$stress $(\mathrm{LK}, 0.03 \mathrm{mM} \mathrm{K}$ ) was applied at three-leaf stage. After 16 days, we observed that the interveinal chlorosis on the third and fourth leaves was more severe in self-grafts of CCRI41/CCRI41 than in reciprocal-grafts of SCRC22/CCRI41 (Figure 1b). Consistently, CCRI41/CCRI41 showed lower chlorophyll content in these two leaves under low $\mathrm{K}^{+}$condition (Figure 1c). Moreover, the biomass of roots, stem and leaves reduced to varying extents under $\mathrm{K}^{+}$deficiency, and CCRI41/CCRI41 was impacted more strongly than SCRC22/CCRI41, especially in terms of root biomass (Figure 1d). The root-shoot ratio of CCRI41/CCRI41 decreased by $3.1 \%$ under low $\mathrm{K}^{+}$ condition, which was similar to previous reports [41]. However, the root-shoot ratio of SCRC22/CCRI41 increased by 3.3\% (Figure 1e). Furthermore, the SCRC22/CCRI41 showed higher $\mathrm{K}^{+}$concentration and accumulation in roots and leaves than CCRI41/CCRI41 under low $\mathrm{K}^{+}$stress, and stored more $\mathrm{K}^{+}$in stem than CCRI41/CCRI41 mainly due to higher dry weight (Figure 1f,g). These results suggest that SCRC22 scion could feedback enhance root growth and $\mathrm{K}^{+}$uptake in CCRI41 rootstock. 
(a)

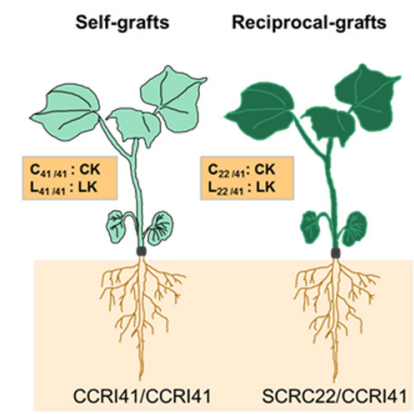

(c)

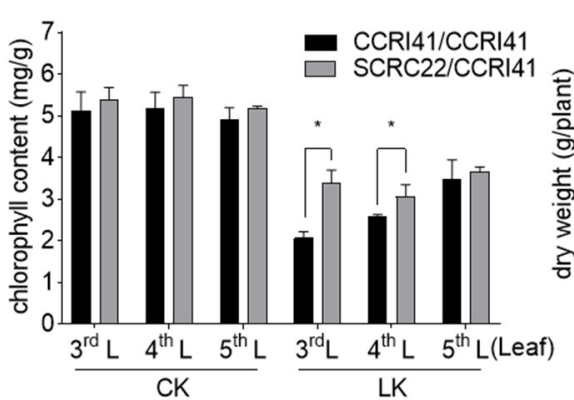

(f)

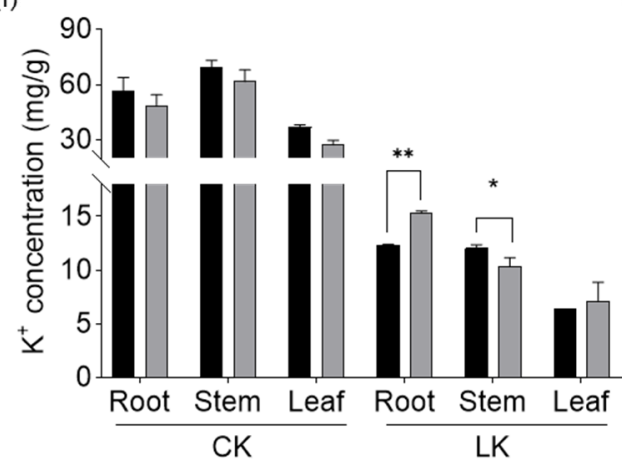

(b)

(d)
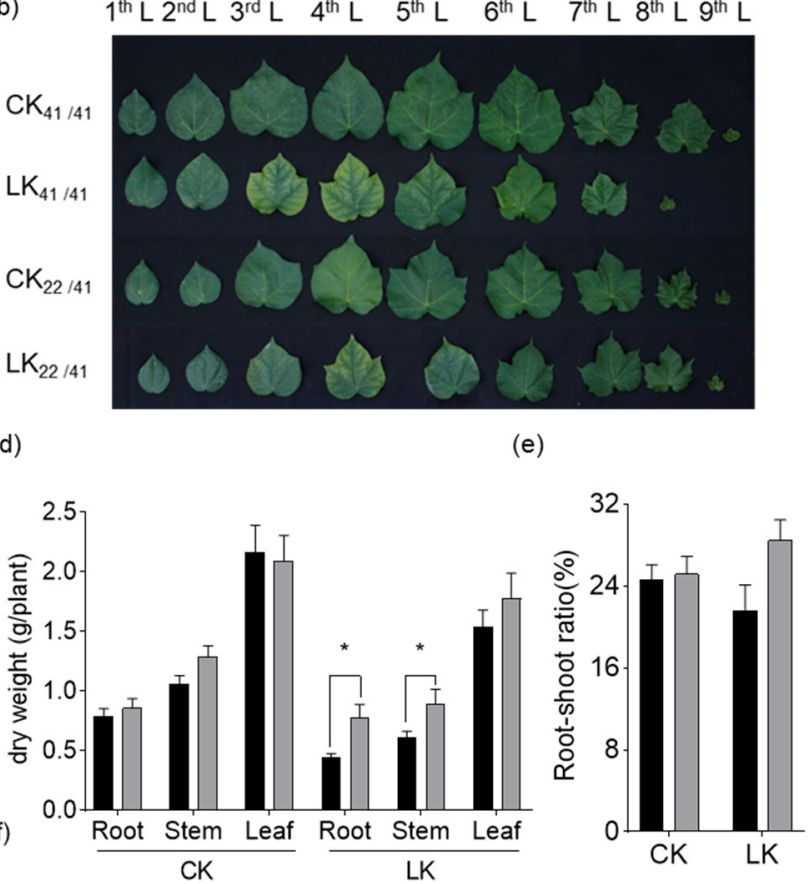

(g)

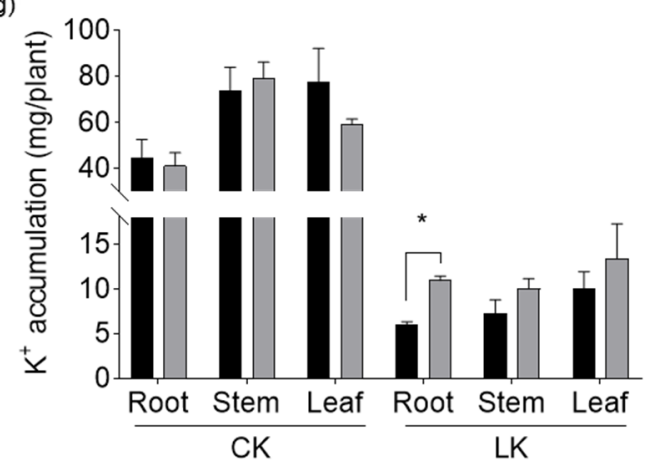

Figure 1. Effects of potassium $\left(\mathrm{K}^{+}\right)$deficiency on CCRI41 (a $\mathrm{K}^{+}$inefficient cotton variety) self-grafts (CCRI41/CCRI41, scion/rootstock) and its reciprocal grafts (SCRC22/CCRI41) with SCRC22 (a K ${ }^{+}$efficient variety). Grafting was performed hypocotyl-to-hypocotyl (a) when the cotyledons of rootstock just fully expanded. Grafts were subjected to low $\mathrm{K}^{+}$(LK, $0.03 \mathrm{mM} \mathrm{K}^{+}$) at the three-leaf stage, with $2.5 \mathrm{mM} \mathrm{K}^{+}$as control (CK). After 16 days, all leaves were photographed (b), and the chlorophyll content in the third (3rd L), fourth (4th L) and fifth (5th L) leaves was measured (c). The dry weight of roots, stem and leaves was recorded (d), and the root-shoot ratio was calculated (e). $\mathrm{K}^{+}$concentration (f) and $\mathrm{K}^{+}$accumulation $(\mathrm{g})$ in roots, stem and leaves were determined or calculated. CK: Control; LK: Low $\mathrm{K}^{+}$treatment. The data are shown as means \pm SD of three replicates $(n=3) ;{ }^{*}$ and ${ }^{* *}$ indicate significant differences at $5 \%$ and $1 \%$ level, respectively.

\subsection{Transcriptome Profiling of CCRI41/CCRI41 and SCRC22/CCRI41 in Response to $K^{+}$Deficiency}

To investigate the changes of gene expression patterns involved in response to $\mathrm{K}^{+}$ deficiency and feedback regulation of $\mathrm{K}^{+}$uptake and root growth in cotton, the roots were sampled after three days of low $\mathrm{K}^{+}$treatment $\left(\mathrm{LK}, 0.03 \mathrm{mM} \mathrm{K}^{+}\right.$) to perform comparative transcriptome analysis. At this time, the expression of the marker gene GhHAK5 (GhD_01G1760) under $\mathrm{K}^{+}$deficiency significantly differed between CCRI41/CCRI41 and SCRC22/CCRI41 (Supplementary Figure S1).

An overview of the sequence assembly after Illumina sequencing is shown in Table S1. A total of 719 million raw reads (697 million clean reads) were generated from 12 root samples. The Q30 (>93\%) values indicated that the quality of sequencing data was sufficient to support further transcriptome analysis. An average $\sim 96 \%$ of these high-quality reads were mapped to the cotton genome (G. hirsutum TM-1(AD) $)_{1}$ [48]. The relationship of 
transcriptome samples for $\mathrm{CK}\left(2.5 \mathrm{mM} \mathrm{K}^{+}\right)$and LK $\left(0.03 \mathrm{mM} \mathrm{K}^{+}\right)$treatments was assessed by the global hierarchical clustering (Figure 2a). To further validate the quality of the gene activity profiles, eight genes were randomly selected to compare their Fragments Per Kilobase Million Mapped Reads (FPKM) values and RT-qPCR data. The results showed that the difference in their relative expression levels evaluated by RT-qPCR between CK and LK were consistent with the difference in FPKM value (Supplementary Figure S2), suggesting the data were appropriate for subsequent analysis.

(a)

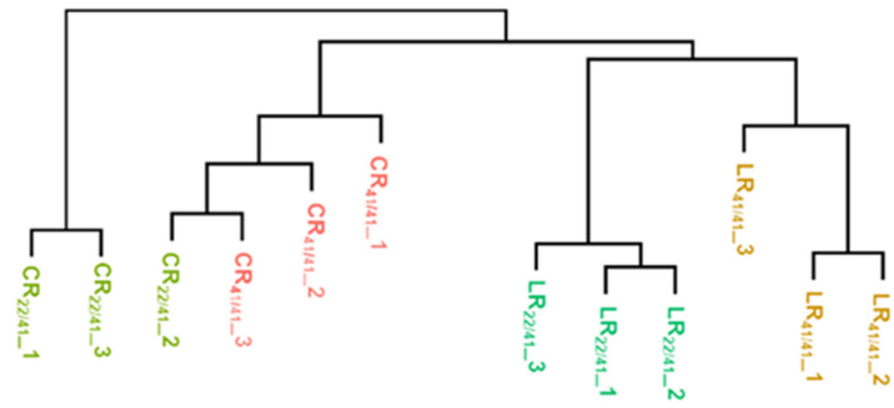

(b)

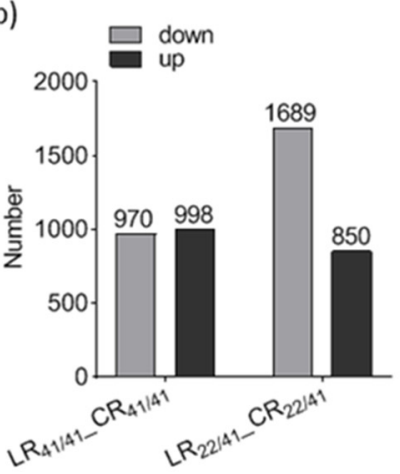

(c)

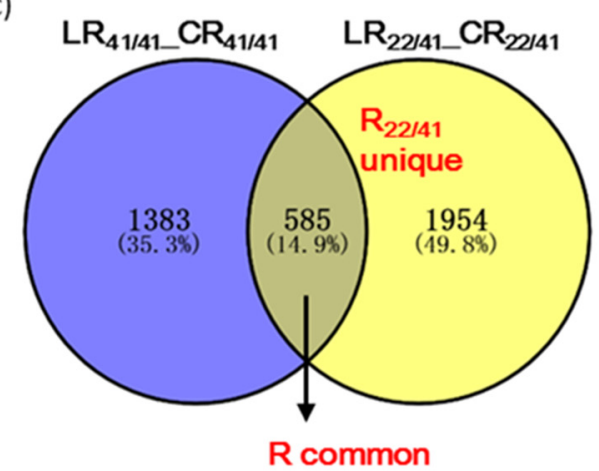

Figure 2. Transcriptome relationships among the roots of CCRI41 self-grafts (CCRI41/CCRI41, scion/rootstock) and reciprocal grafts (SCRC22/CCRI41) under potassium $\left(\mathrm{K}^{+}\right)$deficiency. (a) Cluster dendrogram of the root transcriptomes. (b) Number of differentially expressed genes (DEGs) in the roots of CCRI41/CCRI41 and SCRC22/CCRI41. (c) Venn diagram showing shared and unique DEGs in both grafts. CR and LR: Roots from CK and LK-treated plants; 41/41: CCRI41/CCRI41; 22/41: SCRC22/CCRI41; 1, 2, and 3: Number of replicates. R common: Common DEGs in the roots of both grafts. R22/41 unique: The DEGs specifically identified in the roots of SCRC22/CCRI41.

The differentially expressed genes (DEGs) induced by low $\mathrm{K}^{+}$condition were examined by comparing the expression levels between LK and CK using $p$-value $<0.05$, and $\mid \log _{2}$ (Fold Change) $\mid \geq 1$. Overall, 1968 and 2539 DEGs were identified in roots of

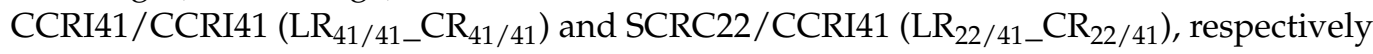
(Figure 2b). A total of 585 DEGs were common in $\mathrm{LR}_{41 / 41} \mathrm{CR}_{41 / 41}$ and $\mathrm{LR}_{22 / 41} \mathrm{CR}_{22 / 41}$, named R common group (Figure 2c). In addition, 1954 DEGs were only identified in $\mathrm{LR}_{22 / 41} \mathrm{CR}_{22 / 41}$, named $\mathrm{R}_{22 / 41}$ unique group (Figure $2 \mathrm{c}$ ). The DEGs in $\mathrm{R}$ common group except those oppositely induced (192) in $\mathrm{LR}_{41 / 41} \mathrm{CR}_{41 / 41}$ and $\mathrm{LR}_{22 / 41} \mathrm{CR}_{22 / 41}$ could be regarded as the basic response to $\mathrm{K}^{+}$deficiency in cotton roots, whereas the DEGs in $\mathrm{R}_{22 / 41}$ unique group and those DEGs oppositely induced in $\mathrm{LR}_{41 / 41} \mathrm{CR}_{41 / 41}$ and $\mathrm{LR}_{22 / 41} \mathrm{CR}_{22 / 41}$ might be the key factors involved in the feedback regulation of $\mathrm{K}^{+}$uptake and root growth.

\subsection{Gene Function Enrichment Analysis of DEGs in Response to $K^{+}$Deficiency}

Gene Ontology (GO) analysis was conducted with the adjusted FDR $<0.05$ as significant enrichment. The DEGs in $\mathrm{R}$ common and $\mathrm{R}_{22 / 41}$ unique group were significantly enriched into 75 and 40 categories, respectively (Supplementary Table S2). For cellular components, the extracellular region (GO: 0005576) was enriched in both groups, and the ubiquitin ligase complex (GO: 0000151) was only enriched in $\mathrm{R}_{22 / 41}$ unique group. For the 
molecular functions category, the oxidoreductase activity (GO: 0016491), heme binding (GO: 0020037), electron carrier activity (GO: 0009055), catalytic activity (GO: 0003824) and nucleic acid binding transcription factor activity (GO: 0001071) were significantly enriched in both groups. For the biological processes category, the metabolic process (GO: 0008152) involved in the most abundant genes, and oxidation-reduction process (GO: 0055114) was the highest enrichment pathway in both groups (Table S2).

The results of the Kyoto Encyclopedia of Genes and Genomes (KEGG) pathway analysis showed that biosynthesis of secondary metabolites, nitrogen metabolism, galactose metabolism and glucosinolate biosynthesis were significantly enriched $(q$-value $<0.05)$ in $R$ common and $\mathrm{R}_{22 / 41}$ unique group (Supplementary Figure S3), consistent with the fact that $\mathrm{K}^{+}$affects the activity of many enzymes and several metabolic pathways [49]. In addition, plant hormone signal transduction and MAPK signaling pathway were only enriched in the $\mathrm{R}$ common group, while $\mathrm{ABC}$ transporters was only enriched in the $\mathrm{R}_{22 / 41}$ unique group (Supplementary Figure S3).

\subsection{DEGs Associated with $\mathrm{Ca}^{2+}, \mathrm{ROS}$, and Phytohormone Signaling Pathway in Response to $\mathrm{K}^{+}$Deficiency}

For the R common group, 10 DEGs related to $\mathrm{Ca}^{2+}$ binding and eight DEGs associated with $\mathrm{CaM}$ binding were identified, but only two putative $\mathrm{Ca}^{2+}$ channel genes and one GhCIPK gene were found. In addition, five DEGs related to $\mathrm{Ca}^{2+}$ binding protein were up-regulated, and five DEGs related to CaM binding protein were down-regulated in the roots of both CCRI41/CCRI41 and SCRC22/CCRI41 (Figure 3a), suggesting that $\mathrm{Ca}^{2+}$ sensors may play important roles in response to $\mathrm{K}^{+}$deficiency.

(a)

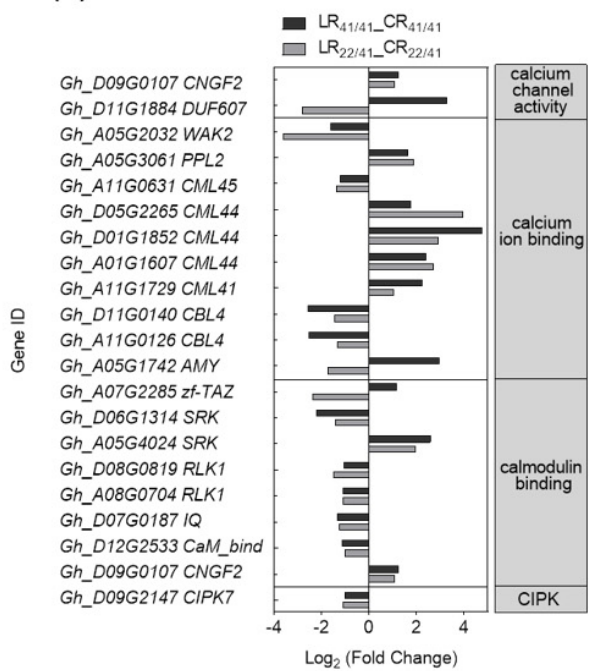

(b)

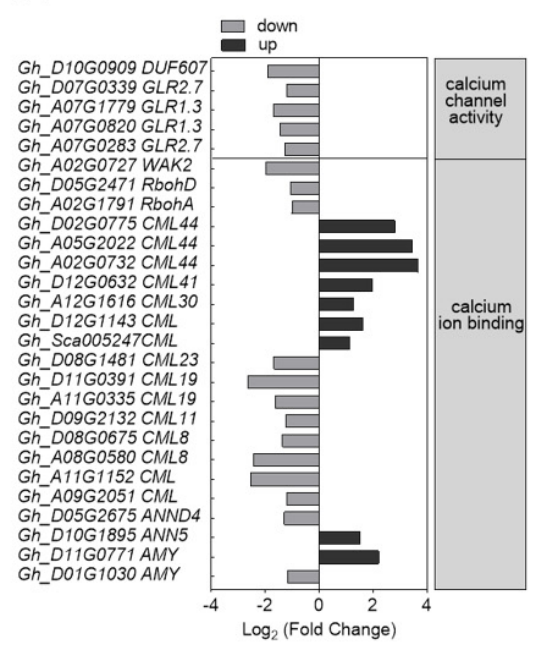

(c)

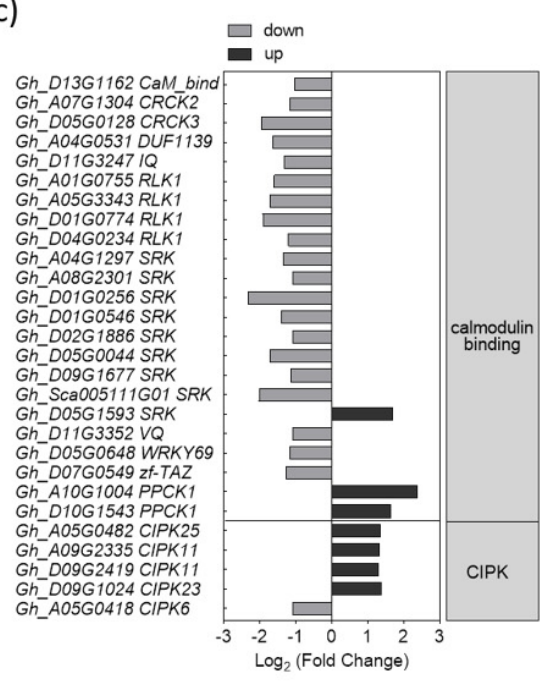

Figure 3. The differentially expressed genes (DEGs) involved in $\mathrm{Ca}^{2+}$ (calcium) signaling in $\mathrm{R}$ common (a) and $\mathrm{R}_{22 / 41}$ unique $(\mathbf{b}, \mathbf{c})$ group. $\mathrm{R}$ common: Common DEGs in roots of CCRI41/CCRI41 (scion/rootstock) and SCRC22/CCRI41 under potassium $\left(\mathrm{K}^{+}\right)$deficiency. R22/41 unique: DEGs specifically identified in roots of SCRC22/CCRI41.

Three DEGs, including one annotated by $\mathrm{Ca}^{2+}$ channel activity (Gh_D11G1884), one related to $\mathrm{Ca}^{2+}$ binding (Gh_A05G1742) and one associated with CaM binding (Gh_A07G2285) were up-regulated in the roots of CCRI41/CCRI41 but down-regulated in the roots of SCRC22/CCRI41 (Figure 3a). Moreover, there were $55 \mathrm{Ca}^{2+}$ related DEGs identified in SCRC22/CCRI41 alone. Among these, several related to $\mathrm{Ca}^{2+}$ and $\mathrm{CaM}$ binding, and $\mathrm{Gh}-$ CIPKs were up-regulated under low $\mathrm{K}^{+}$, which was notable compared with those numerous down-regulated DEGs related to $\mathrm{Ca}^{2+}$ signaling in $\mathrm{R}_{22 / 41}$ unique group (Figure $3 \mathrm{~b}, \mathrm{c}$ ).

A total of eight DEGs related to ROS were identified in the R common group, including six putative GhPOD (peroxidase) genes, one putative GhGST (glutathione S-transferase) gene and one putative GhPRX (peroxiredoxin) gene (Figure 4a). Among the six DEGs associated 
with GhPOD, three of them were down-regulated in both grafts, and another three DEGs were oppositely regulated in two grafts (Figure 4a).

For the $\mathrm{R}_{22 / 41}$ unique group, one GhRbohA (Gh_A02G1791) and one GhRbohD (Gh_D05G2471) were significantly down-regulated (Figure $4 \mathrm{~b}$ ). Also, 24 out of $30 \mathrm{DEGs}$ related to GhPOD, and eight putative GhGST DEGs genes were significantly down-regulated (Figure 4b,c).

(a)

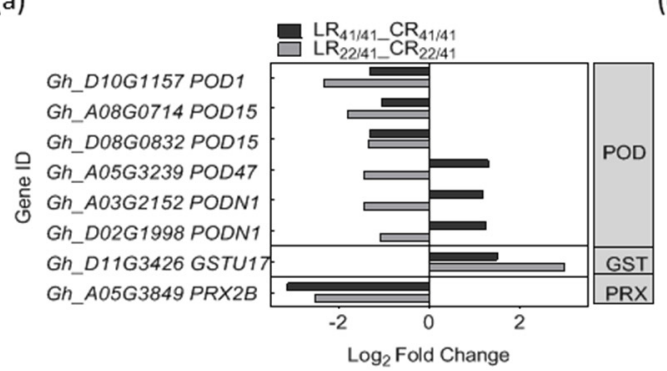

(b)

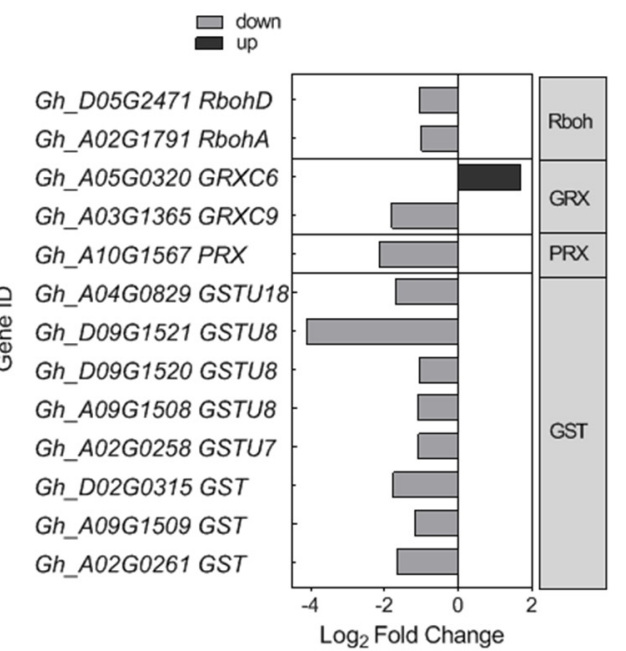

(c)

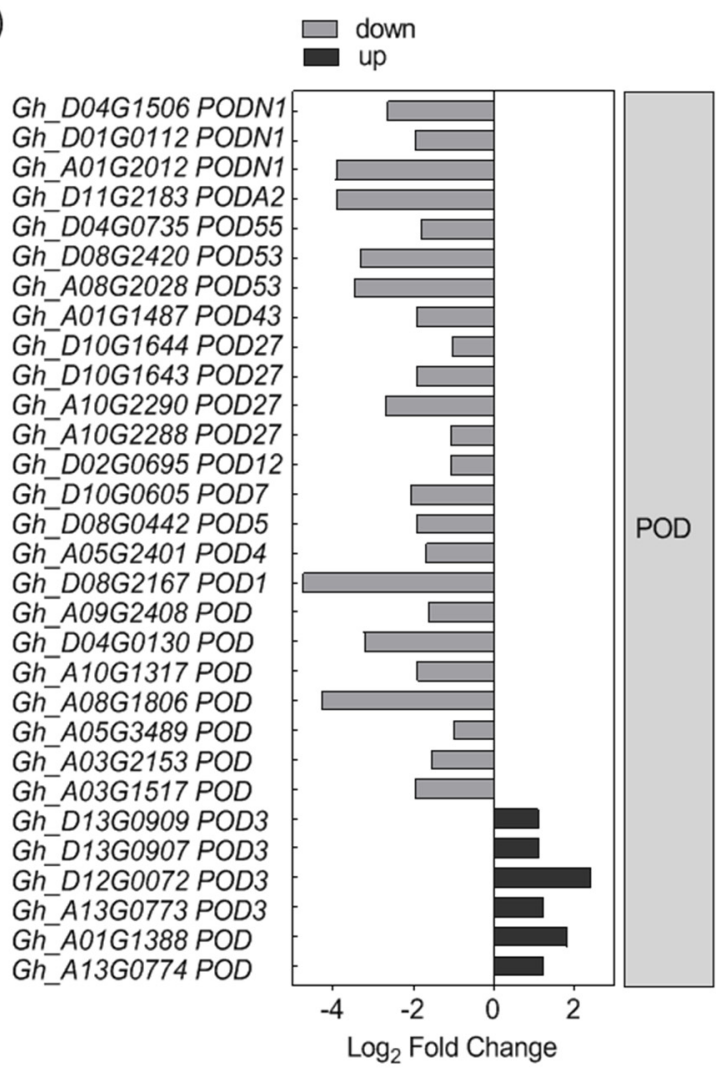

Figure 4. The differently expressed genes (DEGs) involved in ROS (reactive oxygen species) signaling in R common (a) and $\mathrm{R}_{22 / 41}$ unique (b,c) group. R common: Common DEGs in roots of CCRI41/CCRI41 (scion/rootstock) and SCRC22/CCRI41 under potassium $\left(\mathrm{K}^{+}\right)$deficiency. R22/41 unique: DEGs specifically identified in roots of SCRC22/CCRI41.

The 19 and 16 DEGs related to phytohormone were found in $\mathrm{R}$ common and $\mathrm{R}_{22 / 41}$ unique group, respectively (Figure 5). The similarly regulated (both up- or both down-) DEGs in both grafts were associated with auxin (one up-regulated GhSAUR gene), CTK (one down-regulated GhARR12 gene, and two up-regulated GhARR18 genes), ABA (one down-regulated GhSNRK2 gene, and one up-regulated GhPP2C8 gene), ethylene (five down-regulated genes, GhETR2, GhEBF1, two GhERF1B genes, and GhERF15A), and BR (five down-regulated GhTCH4 genes) (Figure 5a).

The one DEG each associated with auxin, CTK, ABA and SA were oppositely regulated (one up- and the other down-) in CCRI41/CCRI41 and SCRC22/CCRI41 (Figure 5a). For the $\mathrm{R}_{22 / 41}$ unique group, the DEGs related to auxin (GhIAA9 and GhGH3), CTK (GhARR2, GhARR12 and GhARR9), ethylene (GhERF15D and GhERF1B), BR (two GhBKI1 genes), and JA (four GhJAZ genes) were significantly down-regulated, whereas the two auxinresponsive genes (GhGH3.17 and GhSAUR) and one ABA receptor gene (GhPYL) were significantly up-regulated (Figure $5 b$ ). 
(a)

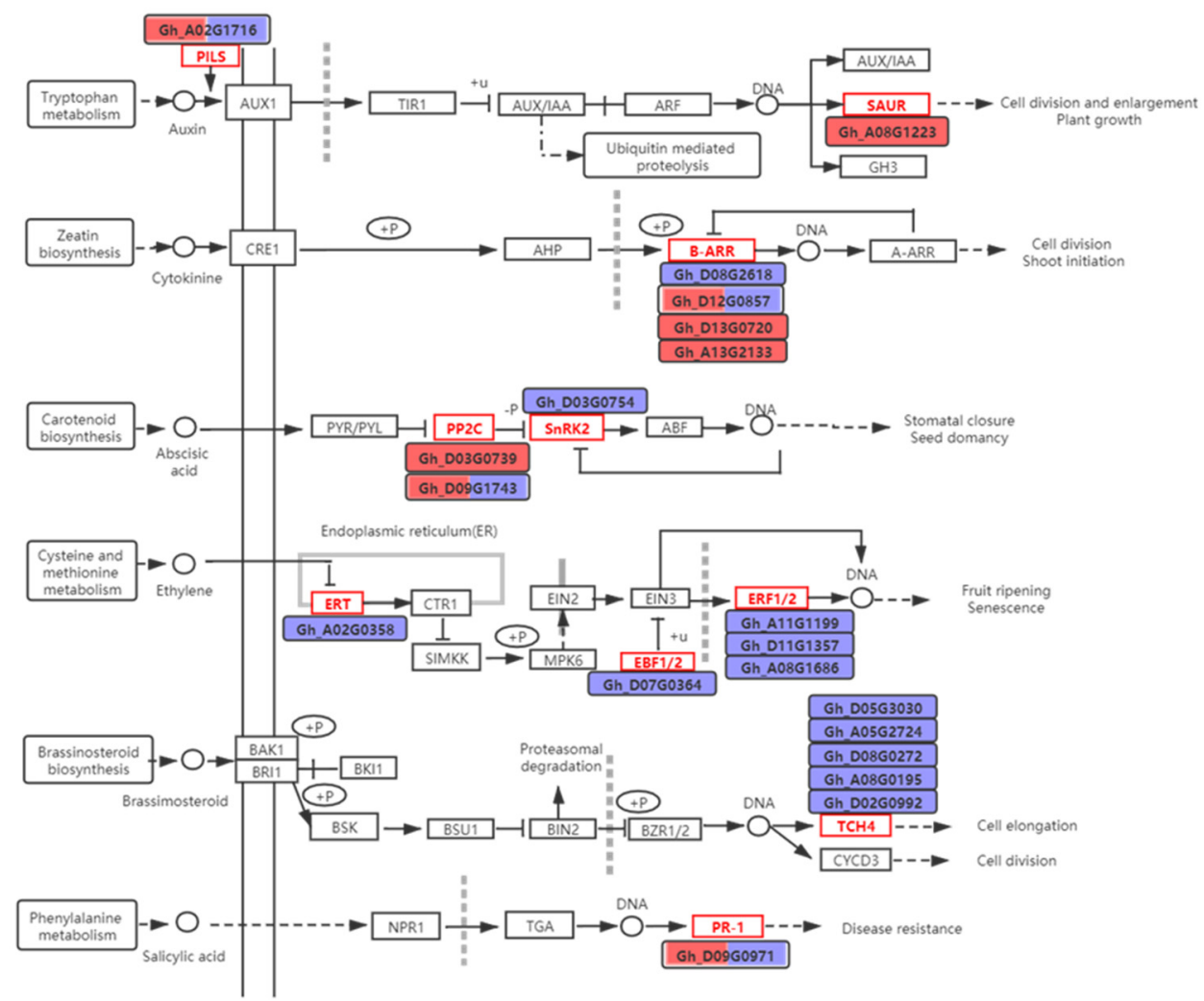

(b)

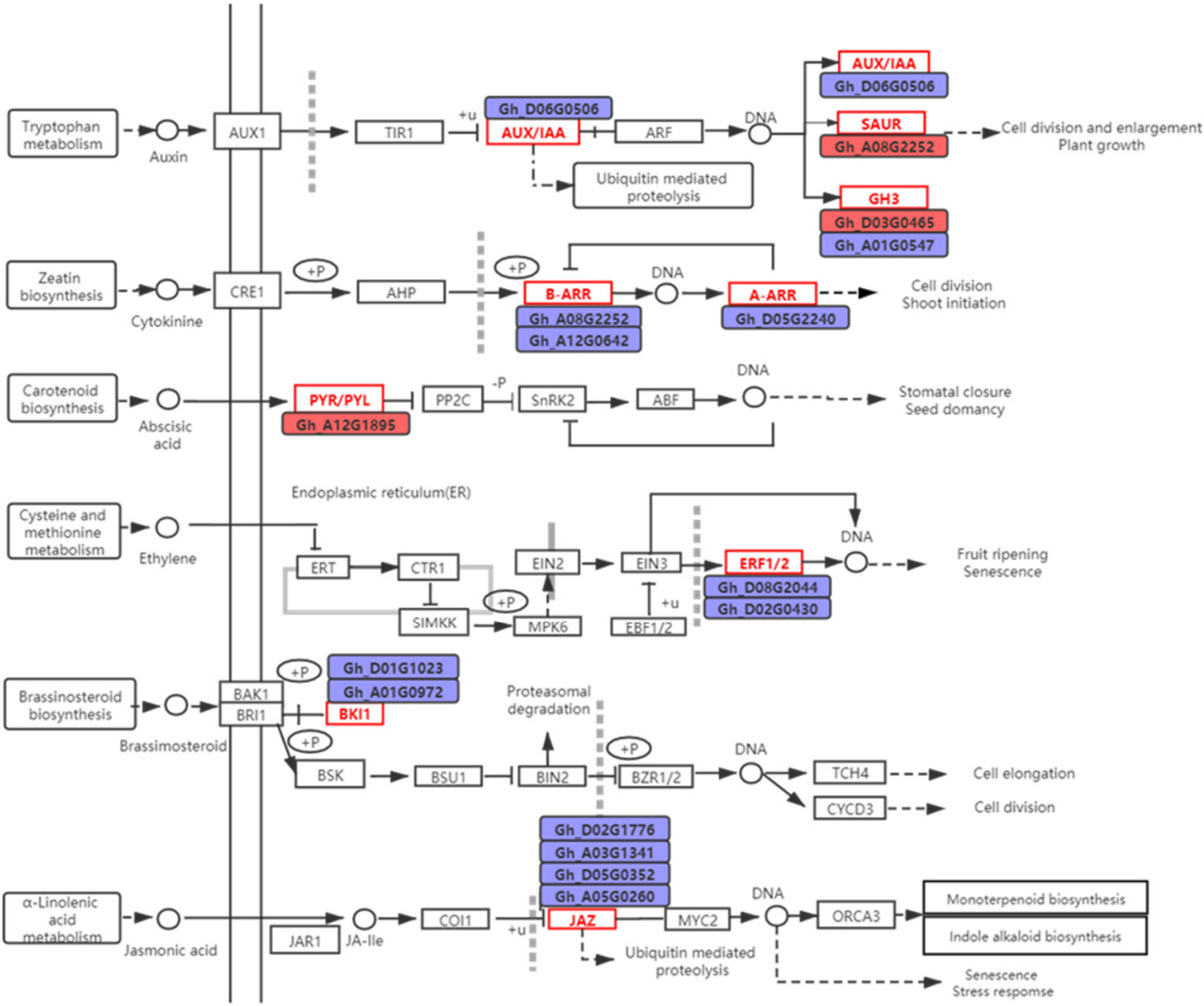

Figure 5. The differentially expressed genes (DEGs) involved in phytohormone signaling in $\mathrm{R}$ common (a) and $\mathrm{R}_{22 / 41}$ unique (b) group. R common: Common DEGs in roots of CCRI41/CCRI41 (scion/rootstock) and SCRC22/CCRI41 under potassium $\left(\mathrm{K}^{+}\right)$deficiency. R22/41 unique: DEGs specifically identified in roots of SCRC22/CCRI41. Red and purple boxes contain genes that were up- and down-regulated, respectively. The red and blue colored boxes contain genes that were oppositely regulated in both grafts, the left and right boxes were assigned to CCRI41/CCRI41 and SCRC22/CCRI41, respectively. The "DNA" in diagram represents undefined genes. 


\subsection{DEGs Associated with Transporters in Response to $K^{+}$Deficiency}

The $\mathrm{K}^{+}$uptake, transportation, and distribution are primarily mediated by $\mathrm{K}^{+}$transporters and $\mathrm{K}^{+}$channels located in the plasma membrane [49]. Therefore, we focused on the genes related to ion transmembrane transporter activity (Figure 6a, Supplementary Figure S4). Unexpectedly, only three GhHAK5 (Gh_A01G1516, Gh_D01G1760 and Gh_D01G1763) and one GhKUP3 (Gh_D04G0700), all from the KUP/HAK/KT family, were significantly up-regulated in the roots of both CCRI41/CCRI41 and SCRC22/CCRI41 after three days of low- $\mathrm{K}^{+}$stress (Figure 6a, Supplementary Figure S4).

(a)

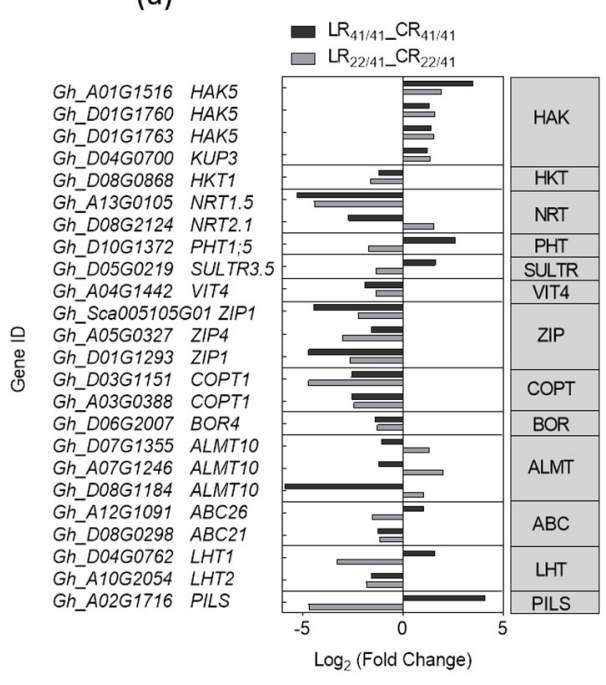

(b)

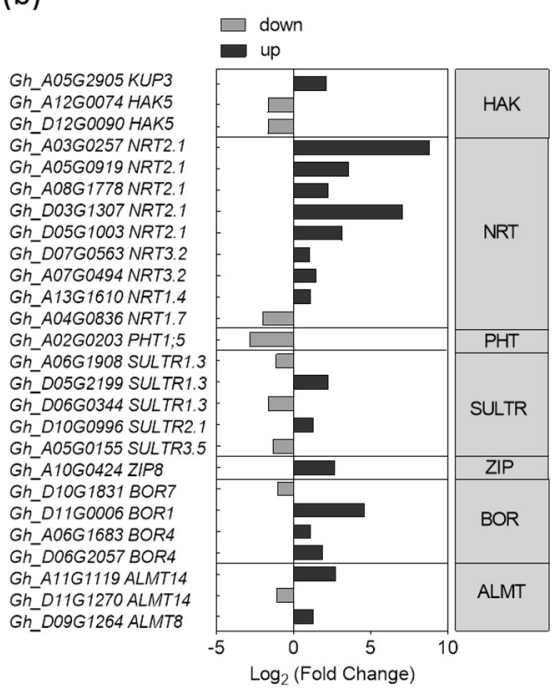

(c)

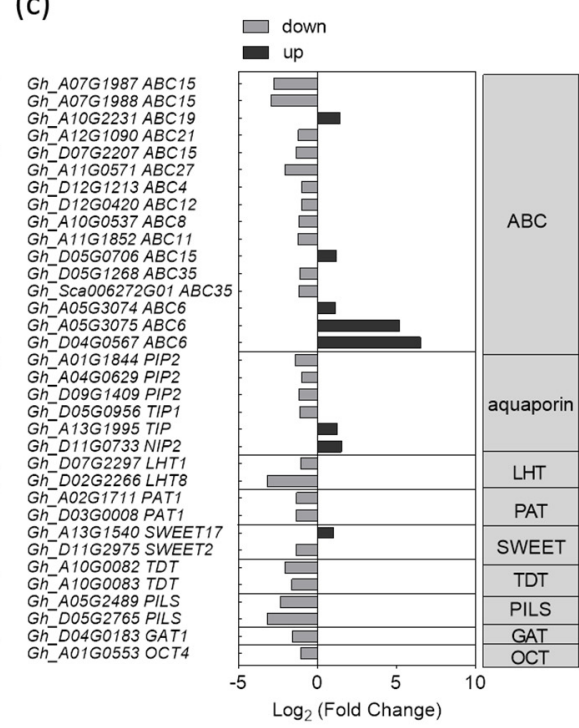

Figure 6. The differentially expressed genes (DEGs) related to transporters in R common (a) and $\mathrm{R}_{22 / 41}$ unique (b,c) group. R common: Common DEGs in roots of CCRI41/CCRI41 (scion/rootstock) and SCRC22/CCRI41 under potassium (K ${ }^{+}$) deficiency. R22/41 unique: The DEGs specifically identified in roots of SCRC22/CCRI41.

In addition, only one GhKUP3 gene (Gh_A05G2905) was significantly up-regulated in $\mathrm{R}_{22 / 41}$ unique group, which was even coupled with the down-regulation of a pair of GhHAK5 genes (Gh_A12G0074 and Gh_D12G0090) (Figure 6b). Considering the higher $\mathrm{K}^{+}$ uptake activity of SCRC22/CCRI41 relative to CCRI41/CCRI41 under low $\mathrm{K}^{+}$condition, such a few specifically up-regulated DEGs in SCRC22/CCRI41 was unexpected.

Among the total of five GhHAK5s regulated by low $\mathrm{K}^{+}$, only the GhHAK5 (Gh_D01G1760), characterized in our previous study [41], showed higher FPKM value $(>16)$, whereas other GhHAK5s had lower FPKM values (<4.6) (Supplementary Figure S4). Also, the FPKM value of two up-regulated GhKUP3 genes (Gh_D04G0700 and Gh_A05G2905) was even higher than that of GhHAK5 (Gh_D01G1760) (Supplementary Figure S4), indicating their important roles in cotton.

Besides $\mathrm{K}^{+}$transporter genes, the expression level of other nutrients transporter genes altered in cotton roots exposed to $\mathrm{K}^{+}$deficient surroundings. For example, one putative $\mathrm{Na}^{+}$transporter gene, one $\mathrm{NO}_{3}{ }^{-}$transporter gene, one iron transporter gene, three zinc transporter genes, two copper transporter genes, and one boron transporter gene were all significantly down-regulated in the roots of CCRI41/CCRI41 and SCRC22/CCRI41 (Figure 6a). The overall nutrient demand is less or root to shoot translocation is reduced under low- $\mathrm{K}^{+}$stress, which probably confers feedback inhibition of expression of related genes in roots [11].

In terms of specific DEGs in the roots of SCRC22/CCRI41, several putative $\mathrm{NO}_{3}{ }^{-}$ transporter genes were found to be predominantly up-regulated, especially two $G h$ NRT2.1 genes (Gh_A03G0257 and Gh_D03G1307) (Figure 6b). In addition, another GhNRT2.1 (Gh_D08G2124) was down-regulated in CCRI41/CCRI41 but up-regulated in SCRC22/CCRI41 under low- $\mathrm{K}^{+}$stress. Also, one of the phosphate $(\mathrm{Pi})$ transporter genes, 
GhPHT1;5 (Gh_A02G0203), was specifically down-regulated in the roots of SCRC22/CCRI41, and another Pi transporter gene GhPHT1;5 (Gh_D10G1372) was down-regulated in SCRC22/CCRI41 but up-regulated in CCRI41/CCRI41. Several aluminum (Al) and boron (B) transporter genes were only identified as up-regulated genes in SCRC22/CCRI41. The other three Al transporter genes (Gh_D07G1355, Gh_A07G1264 and Gh_D08G1184) were up-regulated in SCRC22/CCRI41 but down-regulated in CCRI41/CCRI41. It appears that the down-regulation of $\mathrm{Pi}$ transporter genes and up-regulation of $\mathrm{Al}$ and $\mathrm{B}$ transporter genes may be involved in feedback regulation of $\mathrm{K}^{+}$uptake in cotton roots.

Several GhABC genes were slight down-regulated, while two GhABC6 (Gh_A05G3075 and Gh_D04G0567) were strongly up-regulated (over five-fold) in the roots of SCRC22/ CCRI41 under low $\mathrm{K}^{+}$condition (Figure 6c). Furthermore, two genes related to aquaporin and one gene related to sugar transporter gene GhSWEET17 (Gh_A13G1540) were up-regulated, while four aquaporin genes and one putative sugar transporter gene $G h$ SWEET2 (Gh_D11G2975) were down-regulated beyond the 1-fold cut-off in the roots of SCRC22/CCRI41 alone (Figure 6c).

\subsection{DEGs Associated with Transcription Factors (TFs) in Response to $K^{+}$Deficiency}

As indicated by GO analysis, the nucleic acid binding transcription factor activity (GO: 0001071) was enriched in roots under $\mathrm{K}^{+}$deficiency. A total of 67 and 201 DEGs related to TFs were identified in $\mathrm{R}$ common and $\mathrm{R}_{22 / 41}$ unique group, respectively (Figure S5). These TFs belong to 30 families, and covered almost all types of TFs. For the R common group, the ERFs family had the most DEGs (17), followed by NACs (14), MYBs (8), and WRKYs (6). As shown in Supplementary Figure S3a, 51 TFs in the R common group were similarly regulated (five up-regulated and 46 down-regulated) by $\mathrm{K}^{+}$deficiency in the roots of both grafts, and other $16 \mathrm{TFs}$ were differently regulated in the roots of SCRC22/CCRI41 and CCRI41/CCRI41.

For the $\mathrm{R}_{22 / 41}$ unique group, the most abundant differential expression TFs also belonged to ERFs (41), followed by MYBs (30), WRKYs (25), NACs (18), C2H2s (17), and $b H L H s$ (14) (Supplementary Figure S5b). Interestingly, 78.1\% of the total 201 TFs in this group were down-regulated by low- $\mathrm{K}^{+}$stress.

As GhHAK5 (Gh_D01G1760) is a marker gene induced by $\mathrm{K}^{+}$deficiency [41], the TF-binding sites were predicted from the putative promoter sequences $(2 \mathrm{~kb}$ upstream from the transcriptional start site) of GhHAK5 gene aiming to identify its candidate TFs from differently expressed TFs. For the R common group, four down-regulated TFs (GhWRKY33, GhDOF1.5, and a pair of GhESE3) were predicted to modulate the expression of GhHAK5 (Figure 7a). For the $\mathrm{R}_{22 / 41}$ unique group, two WRKYs (GhWRKY29 and GhWRKY70), three NACs (GhNAC78, GhNAC86 and GhNAC100), and four ERFs (GhERF5, GhERF13, GhERF105, and $G h E R F 1 B$ ) were predicted to be involved in the regulation of GhHAK5 (Figure $7 \mathrm{~b}$ ). These nine TFs were down-regulated under $\mathrm{K}^{+}$deficiency (Figure $7 \mathrm{~b}$ ). 
(a)

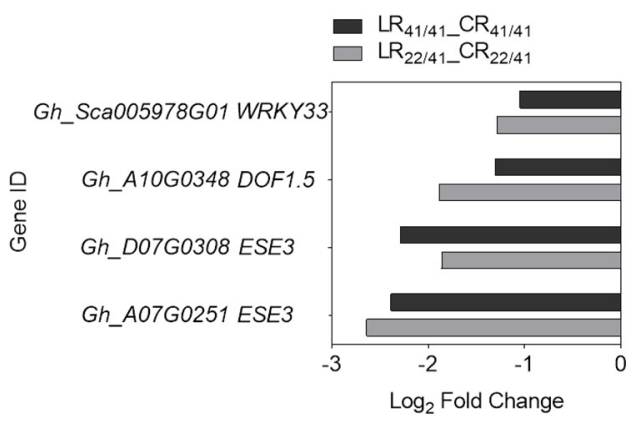

(b)

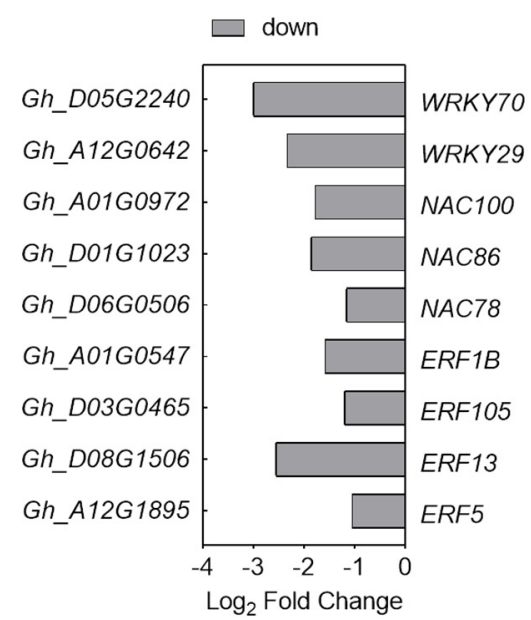

Figure 7. The predicted transcription factors (TFs) that have binding sites in the 2-kb promotor region of the $\mathrm{K}^{+}$transporter gene GhHAK5 (Gh_D01G1760) in $\mathrm{R}$ common (a) and $\mathrm{R}_{22 / 41}$ unique (b) group. $\mathrm{R}$ common: Common DEGs in roots of CCRI41/CCRI41 (scion/rootstock) and SCRC22/CCRI41 under potassium $\left(\mathrm{K}^{+}\right)$deficiency. R22/41 unique: DEGs specifically identified in roots of SCRC22/CCRI41.

\subsection{GhERF15A and GhESE3A Are Probably Involved in Negatively Regulating $K^{+}$Uptake under $K^{+}$Deficiency}

To further understand the roles of TFs in response to low $\mathrm{K}^{+}$, two TFs were selected to characterize the function. One of them was GhERF15A (Gh_A08G1686) that was involved in the ethylene signaling pathway (Figure $5 \mathrm{a}$ ) and down-regulated in the roots of both CCRI41/CCRI41 (1.208-fold) and SCRC22/CCRI41 (2.423-fold) under low $\mathrm{K}^{+}$. The other TF selected was also a putative ethylene response factor GhESE3A (Gh_A07G0251) that was predicted as the TF of GhHAK5 (Figure 7a).

The expression pattern of GhERF15A and GhESE3A as well as GhHAK5 (Gh_D01G1760) was examined in the roots of SCRC22 (non-grafts) at the three-leaf stage. Compared with the plants with sufficient $\mathrm{K}^{+}\left(\mathrm{CK}, 2.5 \mathrm{mM} \mathrm{K}^{+}\right)$, the expression level of GhERF15A and GhESE3A strongly fluctuated over time under low $\mathrm{K}^{+}\left(0.03 \mathrm{mM} \mathrm{K}^{+}\right)$, and showed a largely reversed pattern relative to GhHAK5 (Gh_D01G1760) (Supplementary Figure S6a), suggesting their negative regulation of $\mathrm{K}^{+}$uptake. In addition, the relative expression of GhERF15A and GhESE3A in the roots of GhHAK5 (Gh_D01G1760) RNAi lines was significantly lower than that of wild type S3 (Figure S6b).

We investigated the function of GhERF15A and GhESE3A using virus-induced gene silencing (VIGS) assay in the variety of SCRC22. As shown in Figure 8a,b, a pair of GhERF15 (Gh_A08G1686 and Gh_D08G2044) and a pair of GhESE3 (Gh_A07G0251 and Gh_D07G0308) were effectively silenced, and their expression levels decreased by $62.4 \%$ and $42.7 \%$, respectively. Seedlings with equal fresh weight were selected to determine the $\mathrm{K}^{+}$uptake activity. As expected, VIGS-GhERF15 and VIGS-GhESE3 seedlings showed 38.0\%-52.4\% and $28.5 \%-105.8 \%$ higher net $\mathrm{K}^{+}$uptake rate than VIGS-Ctrl plants (Figure $8 \mathrm{c}, \mathrm{d}$ ). 

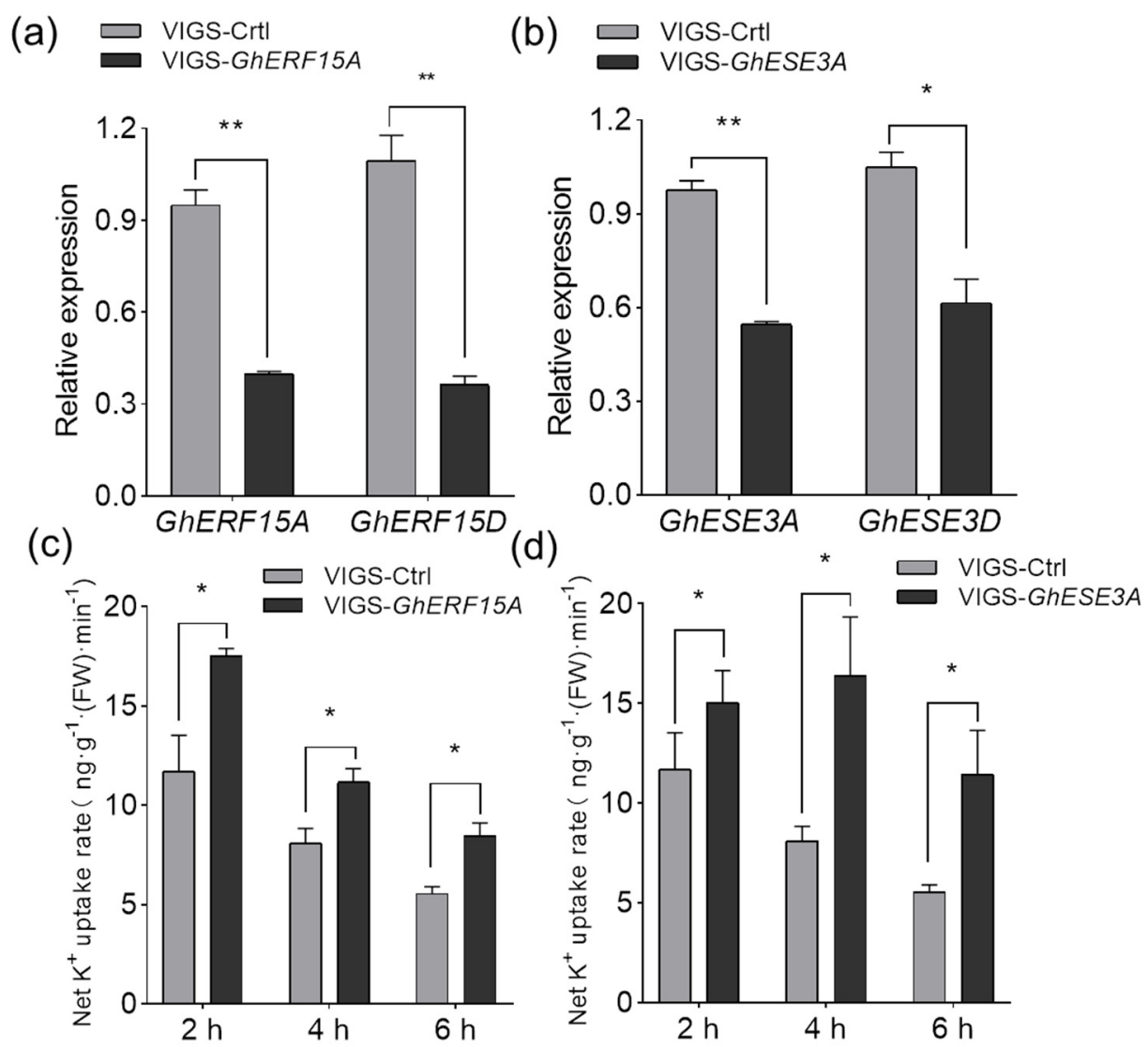

Figure 8. Two members of ethylene response factor (ERF) TFs, GhERF15 and GhESE3, negatively regulate potassium $\left(\mathrm{K}^{+}\right)$uptake in cotton roots. GhERF15 and GhESE3 were silenced in the variety SCRC22 using agrobacterium-mediated virus-induced gene silencing (VIGS) at the cotyledonary stage. The relative expression of GhERF15 (a) and GhESE3 (b) indicates that they were silenced in both $\mathrm{A}$ and $\mathrm{D}$ subgenome. The seedlings at three-leaf stage were moved into $\mathrm{K}^{+}$-starvation solutions for $48 \mathrm{~h}$, then transferred to measuring solution with $0.08 \mathrm{mM} \mathrm{K}^{+}$to determine the net $\mathrm{K}^{+}$uptake rate $(\mathbf{c}, \mathbf{d}) .{ }^{*}$ and ${ }^{* *}$ indicate significant differences at $5 \%$ and $1 \%$ level, respectively.

\section{Discussion}

Compared with nitrogen $(\mathrm{N})$, phosphorus $(\mathrm{Pi})$, iron $(\mathrm{Fe})$, and sulphate $(\mathrm{S})$, the number of DEGs under low- $\mathrm{K}^{+}$stress was less in Arabidopsis and other plants [31,34,50]. However, there is no information on transcriptome analysis in relation to $\mathrm{N}$ and other nutrients in cotton. Some reports showed that the quantity of DEGs under salt stress varied from 3800 to 22,000 in cotton $[51,52]$. Han et al. identified 4627 DEGs in cotton under cadmium (Cd) toxicity [53]. In the present study, around 2000 and $2500 \mathrm{DEGs}$ ( $p$-value $<0.05$, and $\mid \log _{2}$ (Fold Change) $\mid \geq 1$.) were identified in the roots of CCRI41/CCRI41 and SCRC22/CCRI41 following three days of $\mathrm{K}^{+}$deficiency (Figure $2 \mathrm{~b}$ ). The smaller number of DEGs in response to $\mathrm{K}^{+}$deficiency indicates that post-transcriptional regulation and epigenetic modification are also important for plants to respond to low $\mathrm{K}^{+}$stress. Moreover, the number of up- and down-regulated DEGs in CCRI41/CCRI41 was similar, but the number of down-regulated DEGs in SCRC22/CCRI41 was nearly two-fold those up-regulated (Figure 2b), suggesting that the down-regulated of some negative regulators might be important for SCRC22 scion to enhance $\mathrm{K}^{+}$uptake and root growth of CCRI41 rootstock.

3.1. $\mathrm{Ca}^{2+}$ and ROS Signaling Involved in the Response to $\mathrm{K}^{+}$Deficiency and Feedback Regulation of $\mathrm{K}^{+}$Uptake and Root Growth

The elevation of $\left[\mathrm{Ca}^{2+}\right]_{\mathrm{cyt}}$ was elicited by low- $\mathrm{K}^{+}$stress in a distinct spatial and temporal pattern, which could be subsequently decoded by various $\mathrm{Ca}^{2+}$ sensor, and then trigged 
the downstream responses [54]. In this study, the expression level of several putative $\mathrm{Ca}^{2+}$ channel genes specifically reduced in the roots of reciprocal grafts of SCRC22/CCRI41 under low $\mathrm{K}^{+}$condition (Figure $3 \mathrm{~b}$ ), indicating the $\mathrm{Ca}^{2+}$ signal in CCRI41 rootstock was likely attenuated by SCRC22 scion. In contrast to the $\mathrm{Ca}^{2+}$ channel genes, several genes related to $\mathrm{Ca}^{2+}$ binding protein and GhCIPK genes, including GhCIPK23 (Gh_D09G1024), were only induced in the roots of SCRC22/CCRI41 under $\mathrm{K}^{+}$deficiency (Figure 3b,c), suggesting the sensitivity of $\mathrm{Ca}^{2+}$ signaling system may be feedback enhanced by SCRC22 scion. The CIPK23 has been reported to phosphorylate and activate $\mathrm{K}^{+}$channel AKT1 and $\mathrm{K}^{+}$transporter HAK5 in Arabidopsis $[13,27]$. Therefore, the increased expression level of GhCIPK23 may participate in the feedback regulation of $\mathrm{K}^{+}$uptake by modulating the activity of the $\mathrm{K}^{+}$transporters, not excluding $\mathrm{K}^{+}$channels under $\mathrm{K}^{+}$deficiency.

By adding either $\mathrm{H}_{2} \mathrm{O}_{2}$ (a major type of ROS) or DPI (NADPH oxidase blocker) and using the rhd 2 mutant, it was found that $\mathrm{H}_{2} \mathrm{O}_{2}$ plays a role in controlling the expression of certain genes in response to $\mathrm{K}^{+}$deprivation [55]. For instance, ROS can directly regulate AtHAK5 expression either through the TF RAP2.11 (related to AP2 11) [42] or in an ethylene-dependent manner [56]. Recently, Huang et al. demonstrated that RBOHDmediated transcriptional and post-translational activation of plasma membrane $\mathrm{H}^{+}$-ATPase operated upstream of $\mathrm{K}^{+}$uptake transporters HAK5 [57]. However, the specificity of the ROS-induced responses are still not well known, in part because little is known about nutrient signaling cascades in plants [56]. In our study, only a few of DEGs related to ROS, including three down-regulated $P O D$ genes, one down-regulated $P R X$ gene, and one up-regulated GST gene, were identified in the roots of both grafts under $\mathrm{K}^{+}$deficiency (Figure 4a), suggesting that ROS signaling and metabolism may be inactive at the time point we studied [three days after low $-\mathrm{K}^{+}(0.03 \mathrm{mM})$ stress]. In addition, the expression of GhRbohA (Gh_A02G1791) and GhRbohD (Gh_D05G2471) were inhibited in SCRC22/CCRI41 alone under $\mathrm{K}^{+}$deficiency (Figure $4 \mathrm{~b}$ ). In general, ROS not only activates $\mathrm{Ca}^{2+}$ permeable channels but also results in $\mathrm{K}^{+}$efflux from root cells [58]. We consider that the down-regulated GhRbohA and GhRbohD may be beneficial for $\mathrm{K}^{+}$retention in the roots of SCRC22/CCRI41 exposed to $\mathrm{K}^{+}$deficiency by inhibiting $\mathrm{K}^{+}$loss, and thus leading to a higher root $\mathrm{K}^{+}$content compared with CCRI41/CCRI41. Consistent with the down-regulation of GhRbohA and GhRbohD, most of the scavenging ROS genes were down-regulated in SCRC22/CCRI41 under low- $\mathrm{K}^{+}$stress. It perhaps make sense for root growth since the inactive ROS production and elimination may save energy and assimilate.

\subsection{Phytohormone Signaling Involved in Response to $\mathrm{K}^{+}$Deficiency and Feedback Regulation of $\mathrm{K}^{+}$Uptake and Root Growth}

Previous transcriptome studies in rice, tomato, and soybean showed that dozens of DEGs related to auxin responded to $\mathrm{K}^{+}$deficiency $[34,59,60]$. However, in the present study, only a GhSAUR gene (Gh_A08G1223) was induced by low $\mathrm{K}^{+}$in the roots of both grafts. Although the SAUR (small auxin-up RNA) is the largest family of early auxin responsive genes in higher plants, the functions of only few $S A U R$ genes are known owing to functional redundancy among the many family members [61]. The five DEGs related to auxin were specifically up- or down-regulated in SCRC22/CCRI41, including an up-regulated GhGH3 gene (Gh_D03G0465). GH3 proteins are involved in various developmental processes and environmental responses in plants, by modulating the activities or availabilities of plant hormones [62]. In cotton, GhGH3.5 may be involved in drought and salt tolerance [63]. Moreover, one auxin efflux carrier gene GhPILS (Gh_A05G1716) was up-regulated in the roots of CCRI41/CCRI41 but down-regulated in the roots of SCRC22/CCRI41. Considering the greatly different root biomass between the two grafts subjected to prolonged low- $\mathrm{K}^{+}$ stress as well as the important roles of auxin in regulating root growth, we hypothesize that the auxin-related DEGs specifically identified in SCRC22/CCRI41 and the GhPILS (Gh_A05G1716) partly participated in the feedback regulation of root growth.

Some putative components of ABA signaling have been involved in the response to $\mathrm{K}^{+}$ tolerance. PP2C inactivates $\mathrm{K}^{+}$channel, and SRK2E kinase activates $\mathrm{K}^{+}$transporter $[12,21]$. 
An ortholog of AtPP2CA was up-regulated in the roots of M. truncatula plants inoculated with Arbuscular mycorrhizal (AM) under low- $\mathrm{K}^{+}$regime [64]. Proteomic data indicated that the abundance of two PP2Cs was significantly changed in $\mathrm{K}^{+}$-deficient wheat seedlings [25]. In this study, one GhPP2C8 gene (Gh_D03G0739) was up-regulated, and one GhSnRK2 gene (Gh_D03G0754) was down-regulated in the roots of both grafts, suggesting that $\mathrm{ABA}$ signaling may play a negative role in basic response to low $\mathrm{K}^{+}$stress. However, it seems that SCRC22 scion enhanced the ABA signaling in CCRI41 rootstock under $\mathrm{K}^{+}$ deficiency, as indicated by the up-regulated ABA receptor gene GhPYL (Gh_A12G1895), and down-regulated ABA negative regulator GhPP2C51. We speculate that the activated ABA signaling may be associated with the feedback effects of scion on rootstock.

The ethylene pathway is deeply involved in $\mathrm{K}^{+}$uptake and change of root system architecture under $\mathrm{K}^{+}$deficiency [56]. The transcriptome results of Fan et al. indicated that the genes related to ethylene biosynthesis and signaling were involved in the response to low- $\mathrm{K}^{+}$stress in watermelon roots [36]. Among these, several genes were down-regulated at $6 \mathrm{~h}$ of $\mathrm{K}^{+}$deprivation [36], which differed with the results in Arabidopsis [56]. Moreover, no genes related to ethylene were found to respond to $\mathrm{K}^{+}$deficiency in barley roots [35]. In the present study, we identified several down-regulated genes related to ethylene in the roots of both CCRI41/CCRI41 and SCRC22/CCRI41 under low $\mathrm{K}^{+}$condition, including one receptor gene GhERT, one GhEBF1/2 (a negative factor in ethylene pathway) gene, and three GhERF1/2 genes. In terms of specifically regulated genes in SCRC22/CCRI41 roots, two GhERFs were down-regulated under low- $\mathrm{K}^{+}$stress, and one of them, GhERF15A (Gh_A08G1686) is possibly associated with the inhibition of $\mathrm{K}^{+}$uptake (see below). Therefore, its down-regulation may contribute to the feedback enhancement of $\mathrm{K}^{+}$uptake under $\mathrm{K}^{+}$deficiency. The differences in ethylene-related gene expression across plant species could be due to different signaling pathways, or more likely differences in physiological processes involved in response time to low $\mathrm{K}^{+}[56]$.

Jasmonic acid (JA) is involved in response to $\mathrm{K}^{+}$deficiency in Arabidopsis [31], rice [32], and wheat [25]. In our study, four GhJAZ (Jasmonate zim-domain, repress the activity of various TFs) genes (Gh_D02G1776, Gh_A03G1341, Gh_D05G0352, and Gh_A05G0260) were specifically down-regulated in the roots of SCRC22/CCRI41, implying that JA pathway may be involved in the feedback regulation of $\mathrm{K}^{+}$uptake in cotton. In addition, we found that $\mathrm{BR}$ signaling may be involved in the responses to $\mathrm{K}^{+}$conditions in cotton roots, which is a novel finding that has not been reported yet. The five $\mathrm{GhTCH} 4$ genes were down-regulated in the roots of both grafts subjected to low- $\mathrm{K}^{+}$stress. The GhTCH4 gene encodes a BR-regulated xyloglucan endotransgiycosylase (XETs) that plays a role in cell wall modifications in response to environmental stress and during morphogenesis [65]. Therefore, the GhTCH4 genes are likely involved in response to $\mathrm{K}^{+}$deficiency by affecting root cell wall properties in cotton. Furthermore, the expression of two GhBKI1 (a negative regulator in BR signaling pathway) genes (Gh_D01G1023 and Gh_A01G0972) were inhibited in SCRC22/CCRI41 roots alone by low $\mathrm{K}^{+}$, suggesting that SCRC22 scion elicited BR signaling in CCRI41 rootstock under low- $\mathrm{K}^{+}$condition, which likely facilitate the downstream components of BR pathway and thus maintain the root growth of reciprocal grafts.

\subsection{Transporters Involved in the Response to $\mathrm{K}^{+}$Deficiency and Feedback Regulation of $\mathrm{K}^{+}$Uptake}

It was shown that although changes in $\mathrm{K}^{+}$supply (either short- or long-term) affected the expression of a large number of membrane transporter genes, but surprisingly only a few genes belonged to $\mathrm{K}^{+}$transporters that have been reported. Similar results were reported for Arabidopsis [31], wheat and rice [66], and model legume, M. truncatula [63]. Also, only three GhHAK5 genes and one GhKUP3 gene were induced by low $\mathrm{K}^{+}$in the roots of both grafts in this study (Figure 6a). The transcripts of members of the KUP/HAK/KT family usually increased under $\mathrm{K}^{+}$deficiency $[34,36,37]$. Moreover, genotypic differences in $\mathrm{K}^{+}$efficiency were associated with the number and amplitude of up-regulated $\mathrm{K}^{+}$ transporter genes in cotton [41] and wheat [67]. Therefore, the up-regulated HAK-type 
transporters may be a rapid, direct and common strategy for plants to increase $\mathrm{K}^{+}$uptake and overcome $\mathrm{K}^{+}$deficiency.

Besides absorbing $\mathrm{K}^{+}$, the $\mathrm{K}^{+}$transporters, from the KT/KUP/HAK family, also function as auxin carriers or are involved in auxin signaling [22,23]. Recently, it was found that OsHAK5 alters the architecture of rice root and shoot by regulating ATP-dependent transmembrane auxin transport [68], and the $\mathrm{K}^{+}$transporter KUP9 maintains Arabidopsis root meristem activity and root growth by regulating $\mathrm{K}^{+}$and auxin homeostasis in response to low- $\mathrm{K}^{+}$stress [69]. Thus, the differently expressed GhHAK5 genes and GhKUP3 gene in this study may also regulate cotton root development by altering auxin distribution.

Grafting can change the mode of $\mathrm{K}^{+}$absorption in tobacco root, from being dominated by high-affinity transport system (HATS) to being jointly responsible by HATS and lowaffinity transport system (LATS) [70]. In this study, SCRC22 scion also caused some specific expression changes in $\mathrm{K}^{+}$transporter genes in CCRI41 rootstock, including one upregulated (2.14-fold) GhKUP3 gene (Gh_A05G2905) and a pair of down-regulated GhHAK5 genes (Figure $6 \mathrm{~b}$ ). Since the roots of SCRC22/CCRI41 had a significantly higher $\mathrm{K}^{+}$uptake activity than CCRI41/CCRI41 under low $\mathrm{K}^{+}$condition, we speculate that this GhKUP3 may act as an important $\mathrm{K}^{+}$transporter in cotton roots, and participate in the feedback regulation of root $\mathrm{K}^{+}$uptake. In Arabidopsis, the KUP7 is also a major component involved in $\mathrm{K}^{+}$uptake besides AKT1 and HAK5 [71].

The expression of Nitrate transporter 1/peptide transporter (NRT1/PTR) genes regulated by external potassium has been reported for Arabidopsis [31], rice [34], wheat [67], banana [47], and pear [37]. Consistently, we identified several up-regulated GhNRT2.1s in the roots of SCRC22/CCRI41 (Figure 6a, b). This is probably because $\mathrm{K}^{+}$and nitrate $\left(\mathrm{NO}_{3}{ }^{-}\right)$intersect at multiple levels, including uptake, root to shoot transport, and cellular metabolism [72]. Moreover, the recent study by Li et al. revealed that the NRT1.5/NPF7.3 can also function as a proton-coupled $\mathrm{H}^{+} / \mathrm{K}^{+}$antiporter, which mediates root-to-shoot $\mathrm{K}^{+}$translocation [73]. Another nitrate transporter1 member, NRT1.1/NPF6.3, acts as a coordinator in $\mathrm{K}^{+}$uptake and root-to-shoot allocation [74]. Therefore, it seems that the nitrate transporter genes identified in our results could be directly or indirectly involved in the feedback regulation of $\mathrm{K}^{+}$uptake in cotton roots.

The Aluminum activated malate transporter 1 (ALMT1) was found to inhibit root cell elongation by mediating malate exudation under Pi deprivation [75]. In this study, GhALMT10, GhALMT14, and GhALMT8 were up-regulated only in roots of SCRC22/CCRI41 under $\mathrm{K}^{+}$deficiency (Figure 7a,b), which remind that ALMT might be also involved in the feedback regulation of root growth in SCRC22/CCRI41.

There is limited literature on plant sugar transport in response to $\mathrm{K}^{+}$deficiency [58]. In our study, two putative sugar transporter genes GhSWEET17 (Gh_A13G1540) and GhSWEET2 (Gh_D11G2975) differently expressed in the roots of SCRC22/CCRI41 alone under low $\mathrm{K}^{+}$condition; GhSWEET17 was up-regulated and GhSWEET2 was down-regulated (Figure 6c). In Arabidopsis, AtSWEET17 mediates fructose transport across the tonoplast of roots and leaves [76]. AtSWEET2 is localized in the tonoplasts of root cells, particularly in the cortex and epidermis, to play a role in vacuolar glucose sequestration, thereby limiting the efflux of carbon from roots [77]. Considering the obviously bigger roots of SCRC22/CCRI41 relative to CCRI41/CCRI41 under low- $\mathrm{K}^{+}$stress, sugar transport may be involved in feedback enhancement of root growth by regulating assimilate distribution among organs.

\subsection{Transcription Factors Involved in the Response to $\mathrm{K}^{+}$Deficiency and Feedback Regulation of $\mathrm{K}^{+}$Uptake and Root Growth}

Transcription factors (TFs) may act as molecular switches to regulate clusters of gene expression in response to stress in higher plants [78]. It has been known that the Phosphate starvation response 1 (PHR1) is the key TF in Pi starvation; it coordinates with other MYBs and WRKYs to up- or down-regulate a subset of Pi starvation-induced (PSI) genes in response to Pi deficiency [79]. In addition, there is a key TF, NIN-like 7 protein (NLP7), 
and a series of other TFs implicated in the control of genes related to $\mathrm{NO}_{3}{ }^{-}$transport and metabolism under low $\mathrm{NO}_{3}{ }^{-}$conditions [80]. However, only a few TFs have been found to directly regulate the expression of $\mathrm{K}^{+}$transporter genes so far. Besides AtRAP2.11 and AtARF2 that were known positively and negatively regulating AtHAK5 respectively in Arabidopsis, four other TFs, Dwarf and Delayed Flowering 2 (DDF2), Jagged Lateral Organs (JLO), Transcription initiation Factor II_A gamma chain (TFII_A), and basic Helix-Loop-Helix 121 (bHLH121), binding to the HAK5 promoter to activate HAK5 expression, were isolated via activation tagging of the $A t H A K 5$ promoter fused with a luciferase reporter gene [81]. Recently, the TF MYB59 was found to bind directly to the promoter of NPF7.3 (a protoncoupled $\mathrm{H}^{+} / \mathrm{K}^{+}$antiporter, mediates root-to-shoot $\mathrm{K}^{+}$translocation) and respond to low- $\mathrm{K}^{+}$ stress by regulating the expression of NPF7.3 in Arabidopsis roots [71]. In the case of rice, OsMYBc has been identified using a yeast one-hybrid approach, which can bind to the OsHKT1;1 promoter and then activate its transcription [82]. In addition, the overexpression of SiMYB3 from foxtail millet can promote the root elongation and improve $\mathrm{K}^{+}$deficiency tolerance in transgenic Arabidopsis [83].

A wide array of transcriptome studies found dozens to hundreds of differently expressed TFs in response to $\mathrm{K}^{+}$deficiency in plants, and MYB, ERF and WRKY families were most commonly identified $[37,47,59,65,84]$, suggesting their implications in coping with external $\mathrm{K}^{+}$deprivation. In this study, we identified 67 and 201 DEGs encoding TFs in the roots of both grafts and only in the roots of SSCRC22/CCRI41 under $\mathrm{K}^{+}$deficiency (Supplementary Figure S5). The members of ERF family were the most numerous either in both grafts or in SCRC22/CCRI41 alone, which was followed by NAC and MYB families in the former or MYB and WRKY families in the latter. Therefore, it could be supposed that the transcription regulation strategy of feedback improvement of $\mathrm{K}^{+}$uptake was different from that of basic/common response to low $\mathrm{K}^{+}$in cotton roots.

Only 10-20\% differently expressed TFs were up-regulated by low $\mathrm{K}^{+}$in our study, and majority was down-regulated, suggesting the TFs respond to low- $\mathrm{K}^{+}$stress probably through relief of certain transcription inhibitions in cotton roots. Some previous reports showed similar results [36].

Importantly, we preliminarily characterized the function of two ERF TFs, GhERF15 and GhESE3, in the present study, and found that they negatively regulate $\mathrm{K}^{+}$uptake in cotton roots. Although GhESE3A was predicted to bind to the promotor of GhHAK5 (Gh_D01G1760), the results of dual luciferase reporter assay in cotton protoplast indicated that both GhERF15A and GhESE3A cannot significantly regulate the expression of GhHAK5. Since the nature of plant transcription regulatory network is complex and redundant [85], we guess that GhERF15A and GhESE3A may regulate GhHAK5 by forming complexes with other proteins, or directly regulate other target genes to participate in the $\mathrm{K}^{+}$absorption in cotton roots.

Future work will further characterize the functions of the two selected TFs above and other important candidate genes, and will screen more candidate genes in response to $\mathrm{K}^{+}$limitation and involved in feedback regulation of $\mathrm{K}^{+}$uptake and root growth by using SCRC22 self-grafts (SCRC22/SCRC22) and another reciprocal-graft CCRI41/SCRC22 besides CCRI41/CCRI41 and SCRC22/CCRI41. Also, the dynamic transcriptome patterns over time will be explored to better understand the molecular mechanisms underlying $\mathrm{K}^{+}$ uptake and its regulation pathways.

\section{Materials and methods}

\subsection{Plant Materials and Growth Condition}

$\mathrm{A} \mathrm{K}^{+}$efficient cotton variety, SCRC22 (developed by the Cotton Research Center, Shandong Academy of Agricultural Sciences) and a $\mathrm{K}^{+}$inefficient variety, CCRI41 (developed by the Cotton Research Institute, Chinese Academy of Agricultural Sciences) were selected as materials. The self-grafts of CCRI41 (CCRI41/CCRI41, scion/rootstock) and reciprocal grafts SCRC22/CCRI41 were used for phenotype determination and RNA-Seq (RNA sequencing) analysis. When the cotyledons of rootstock just fully expanded (the 
scion being four days younger), the grafting was performed hypocotyl-to-hypocotyl as described previously [86].

In addition, SCRC22 (non-grafts) and the RNAi lines of $\mathrm{K}^{+}$transporter GhHAK5 (Gh_D01G1760) were used to show the expression pattern of some candidate genes, and the function of candidate genes was characterized in SCRC22 via VIGS (virus-induced gene silencing) assay.

The hydroponic experiments were conducted in a growth chamber under the following conditions: $14 \mathrm{~h}$ light $/ 10 \mathrm{~h}$ dark photoperiod, $28 \pm 2{ }^{\circ} \mathrm{C}$ day $/ 22 \pm 2{ }^{\circ} \mathrm{C}$ night temperatures, relative humidity $65 \%$ and $400 \mu \mathrm{mol} \cdot \mathrm{m}^{-2} \cdot \mathrm{s}^{-1}$ photosynthetically active radiation. The modified Hoagland's solution was used in this study, containing $2.5 \mathrm{mM} \mathrm{KNO}_{3}$, $2.5 \mathrm{mM} \mathrm{Ca}\left(\mathrm{NO}_{3}\right)_{2}, 1 \mathrm{mM} \mathrm{MgSO}_{4}, 0.5 \mathrm{mM}\left(\mathrm{NH}_{4}\right) \mathrm{H}_{2} \mathrm{PO}_{4}, 0.1 \mathrm{mM}$ Fe Na EDTA, and micronutrients $\left(2 \times 10^{-4} \mathrm{mM} \mathrm{CuSO}_{4}, 1 \times 10^{-3} \mathrm{mM} \mathrm{ZnSO}_{4}, 2 \times 10^{-2} \mathrm{mM} \mathrm{H}_{3} \mathrm{BO}_{3}, 5 \times 10^{-6} \mathrm{mM}\right.$ $\left(\mathrm{NH}_{4}\right)_{6} \mathrm{Mo}_{7} \mathrm{O}_{24}$ and $\left.1 \times 10^{-3} \mathrm{mM} \mathrm{MnSO}_{4}\right)$. During growth period of seedlings, the solutions were changed every four days, and deionized water was added daily to replace the water lost by evapo-transpiration. Oxygen was constantly provided to the solutions by air pump.

\subsection{Photography of $\mathrm{K}^{+}$Deficiency Symptoms and Measurement of Biomass, Chlorophyll and $\mathrm{K}^{+}$Content}

The grafts of CCRI41/CCRI41 and SCRC22/CCRI41 were raised in solutions containing $2.5 \mathrm{mM} \mathrm{K}^{+}$until the three-leaf stage. Then, half of them was subjected to low $\mathrm{K}^{+}\left(\mathrm{LK}, 0.03 \mathrm{mM} \mathrm{K}^{+}\right.$), and the other half was continually cultured in normal condition $\left(\mathrm{CK}, 2.5 \mathrm{mM} \mathrm{K}^{+}\right)$. After 16 days of $\mathrm{K}^{+}$deficiency, seedlings were harvested. All leaves were photographed to present the effects of $\mathrm{K}^{+}$limitation on leaf color and chlorosis. In addition, $0.2 \mathrm{~g}$ leaf disks were collected from the third, fourth and fifth true leaves to determine chlorophyll content following Tang et al [87]. Then, seedlings were separated into roots, stem and leaves, and dried at $80{ }^{\circ} \mathrm{C}$. After weighing the dry weight, the $\mathrm{K}^{+}$ concentration of three subsamples from each organ were measured by an atomic absorption spectrophotometer (Z-2000, Hitachi, Japan) [88]. The $\mathrm{K}^{+}$concentration times dry weight was $\mathrm{K}^{+}$accumulation. Each treatment had three biological replicates, and each replicate included three plants.

\subsection{RNA Isolation, Library Construction, and Sequencing}

The grafted seedlings were subjected to low $\mathrm{K}^{+}\left(\mathrm{LK}, 0.03 \mathrm{mM} \mathrm{K}^{+}\right)$at the three-leaf stage, with $2.5 \mathrm{mM} \mathrm{K}^{+}$as control (CK). After three days of LK stress, the fine roots (diameter less than $1 \mathrm{~mm}$ ) were sampled and immediately frozen in liquid nitrogen, then stored at $-80^{\circ} \mathrm{C}$. Each treatment had three biological replicates, and each replicate was collected from five plants.

Total RNA was extracted and purified using the EASYspin Plus Complex Plant RNA Kit (Aidlab Biotech, Beijing, China). RNA purity was checked using the kaiaoK5500 ${ }^{\circledR}$ spectrophotometer (Kaiao, Beijing, China). RNA quality was assessed by Nano 6000 Assay Kit of the Agilent Bioanalyzer 2100 system (Agilent Technologies, Santa Clara, CA, USA). Thereafter, $3 \mu \mathrm{g}$ high-quality total RNA was used as input material for library construction and Illumina sequencing.

Following the manufacturer's recommendations, sequencing libraries were generated using NEBNext ${ }^{\circledR}$ Ultra $^{\mathrm{TM}}$ RNA Library Prep Kit for Illumina ${ }^{\circledR}$ (\#E7530L, NEB, Ipswich, MA, USA) and index codes were added to attribute sequences to each sample. The RNA concentration of library was measured using Qubit ${ }^{\circledR} R N A$ Assay Kit in Qubit ${ }^{\circledR} 3.0$ to preliminarily quantify and then dilute to $1 \mathrm{ng} / \mu \mathrm{L}$. Insert size was assessed using the Agilent Bioanalyzer 2100 system (Agilent Technologies, Santa Clara, CA, USA). After cluster generation, the library preparations were sequenced on the Illumina platform, with an average reading length of PE150. The library construction, and sequencing were performed by Anoroad Technologies (Beijing, China). 


\subsection{Read Mapping and Analysis of RNA-Seq}

The clean reads were obtained by removing the junction sequences and low-quality sequences. The remaining reads were mapped to the G. hirsutum genome [48] using HISAT2 [89]. Reads count for each gene in each sample was done with HTSeq v0.6.0, and FPKM (Fragments Per Kilobase Millon Mapped Reads) was then calculated to estimate the expression level of genes in each sample [90]. DESeq2 (https://bioconductor.org/ packages/release/bioc/html/DESeq2.html) (accessed on 8 December 2020) was used to estimate the expression level of each gene by the linear regression, then the $p$-value was calculated with Wald test. Finally, the $p$-value was corrected by the Benjamini and Hochberg method [91]. Genes with $p$-value $<0.05$ and $\mid \log _{2}$ (Fold Change) $\mid \geq 1$ were identified as DEG [91].

Sample relationships were analyzed by hierarchical clustering that was performed by the OmicShare (https://www.omicshare.com/tools/home/index/index.html) (accessed on 9 December 2020) with the HCA method.

\subsection{Functional Annotation of DEGs}

To further assign and annotate the DEGs, Gene ontology (GO) enrichment analysis (http:/ / www.geneontology.org/) (accessed on 13 November 2020) and Kyoto Encyclopedia of Genes and Genomes (KEGG) pathway analysis (http:/ /www.kegg.jp/) (accessed on 8 December 2020) were used to identify the genes in each library $[92,93]$.

\subsection{Reverse Transcription Quantitative Polymerase Chain Reaction (RT-qPCR) Analysis}

To test the quality of RNA-seq sequencing, the full-length cDNA of randomly selected genes was synthesized using Oligo d (T) primer and M-MLV reverse transcriptase (Takara, Kusatsu, Japan) with $2 \mu \mathrm{g}$ RNA. Then RT-qPCR was conducted in an Applied Biosystems 7500 Fast Real-Time PCR System (Applied Biosystems, Waltham, CA, USA) using SYBR ${ }^{\circledR}$ Premix Ex Taq ${ }^{\mathrm{TM}}$ (Takara, Kusatsu, Japan) following conditions: $95^{\circ} \mathrm{C}$ for $30 \mathrm{~s}, 40$ cycles of $95^{\circ} \mathrm{C}$ for $5 \mathrm{~s}, 60^{\circ} \mathrm{C}$ for $34 \mathrm{~s}$, and $95^{\circ} \mathrm{C}$ for $15 \mathrm{~s}, 60^{\circ} \mathrm{C}$ for $60 \mathrm{~s}$, then $95^{\circ} \mathrm{C}$ for $30 \mathrm{~s}$, finally $60{ }^{\circ} \mathrm{C}$ for $10 \mathrm{~s}$. A melting curve was performed from 60 to $95^{\circ} \mathrm{C}$ to check the specificity of the amplified product. GhActin 9 was used to normalize gene expression levels. The relative gene expression was calculated using the $2^{-\Delta \Delta \mathrm{Ct}}$ method [94]. The primers for RT-qPCR are listed in Supplementary Table S3.

\subsection{Prediction of TFs Binding to the Promoter of $K^{+}$Transporter GhHAK5 (Gh_D01G1760)}

Putative promoter sequences ( $2 \mathrm{~kb}$ upstream from the transcriptional start site) of GhHAK5 were searched in Cottongen (https:/ / www.cottongen.org/retrieve/sequences) (accessed on 18 February 2021). Then, the prediction of TF-binding sites in this region was performed with the online software PlantRegMap (http:/ / www.plantregmap.cbi.pku.edu. cn) (accessed on 18 February 2021) [95].

\subsection{Detect the Transcription Pattern of Candidate Genes}

Seedlings of SCRC22 (non-grafts) were exposed to low $\mathrm{K}^{+}\left(0.03 \mathrm{mM} \mathrm{K}^{+}\right)$at the threeleaf stage, with $2.5 \mathrm{mM} \mathrm{K}^{+}$as control. Then the fine roots with diameter less than $1 \mathrm{~mm}$ were collected at $0,6,12 \mathrm{~h}$, and 1,5, $7 \mathrm{~d}$. In addition, the fine roots of RNAi lines of $\mathrm{K}^{+}$ transporter GhHAK5 (Gh_D01G1760) grown in solutions with $2.5 \mathrm{mM} \mathrm{K}^{+}$were sampled at the three-leaf stage. The relative expression of candidate genes was determined by RT-qPCR as above.

\subsection{Determination of Net $K^{+}$Uptake Rate in Virus-Induced Gene Silencing (VIGS ) Plants}

The Agrobacterium-mediated VIGS was operated according to the method described in Wang et al [41]. Plants of VIGS-candidate genes and VIGS-Ctrl with equal fresh weight were moved into $\mathrm{K}^{+}$-starvation solutions $\left(200 \mathrm{mM} \mathrm{CaSO}_{4}, 5 \mathrm{mM}\right.$ MES (pH 5.7) adjusted with Tris) at the three-leaf stage for $48 \mathrm{~h}$. The solutions were refreshed once after $24 \mathrm{~h}$. Each single plant was then transferred to one foil-covered flask containing 
$50 \mathrm{~mL}\left(\mathrm{~V}_{1}\right)$ solutions with $0.08 \mathrm{mM} \mathrm{K}^{+}\left(\mathrm{C}_{1}\right)$. The volume $\left(\mathrm{V}_{2}\right)$ and $\mathrm{K}^{+}$concentration $\left(\mathrm{C}_{2}\right)$ of solutions were accurately measured after 2,4 , and $6 \mathrm{~h}(\mathrm{~T})$, then the root fresh weight (FW) of each plant were recorded. The net $\mathrm{K}^{+}$uptake rate $(\mathrm{R})$ was calculated as: $\mathrm{R}=\left(\mathrm{V}_{1} \times \mathrm{C}_{1}-\mathrm{V}_{2} \times \mathrm{C}_{2}\right) /(\mathrm{FW} \times \mathrm{T})$. Each treatment had four biological replicates.

\subsection{Statistical Analysis}

The data were statistically analyzed using SPSS 21.0 (SPSS Inc., Chicago, IL, USA). Mean values were compared using Duncan multiple comparison procedure at the $1 \%$ and $5 \%$ level of probability.

\section{Conclusions}

In conclusion, the expression of hundreds of genes changed in response to $\mathrm{K}^{+}$deficiency in cotton roots basically, and more than two thousand genes were associated with feedback regulation of $\mathrm{K}^{+}$uptake and root growth. Figure 9 shows the important genes related to $\mathrm{Ca}^{2+}, \mathrm{ROS}$, and phytohormone signaling as well as transcription factors (TFs) and transporters, which were involved in these physiological processes. The components of brassinolide (BR) signaling, GhTCH4 and GhBKI1s, were first found to participate in the response to low $\mathrm{K}^{+}$stress and feedback regulation of $\mathrm{K}^{+}$uptake and root growth in plants. In addition, GhKUP3s, a member of KUP/HAK/KT family of $\mathrm{K}^{+}$transporters, may play important roles in cotton besides GhHAK5s. The two ERF family TFs, GhERF15 and GhESE3, were preliminary demonstrated to negatively regulate $\mathrm{K}^{+}$uptake in cotton through VIGS assay. Finally, the up-regulated genes related to CIPK (CBL-interacting protein kinases) and $\mathrm{NO}_{3}{ }^{-}$transporters under low $\mathrm{K}^{+}$possibly contribute to the feedback enhancement of $\mathrm{K}^{+}$uptake in cotton roots.

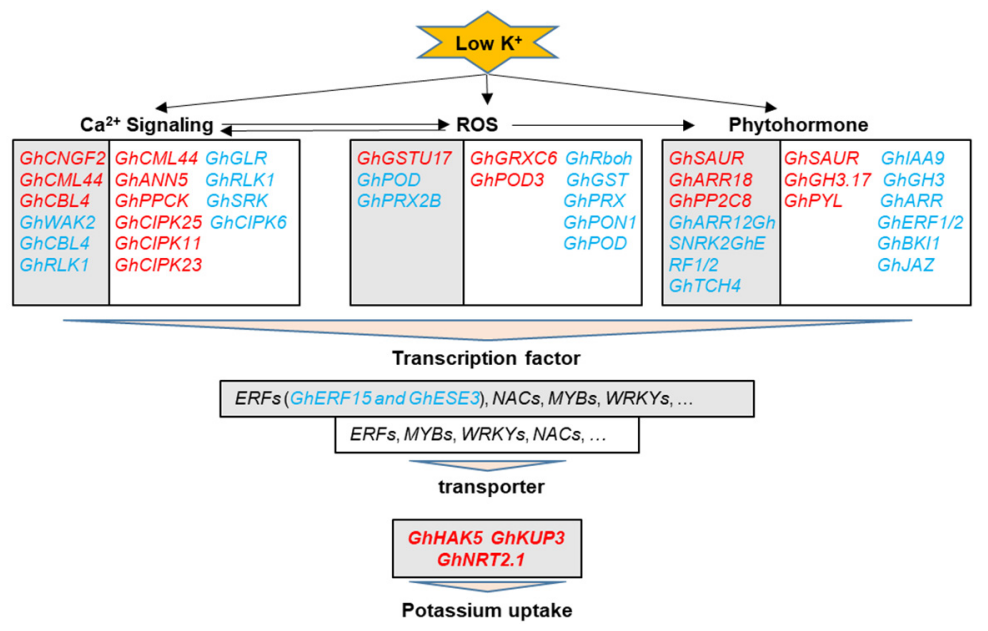

Figure 9. A model of transcription regulation involved in response to potassium $\left(\mathrm{K}^{+}\right)$deficiency and feedback regulation of $\mathrm{K}^{+}$uptake and root growth in cotton. Genes within the light grey box show the same responses to low $\mathrm{K}^{+}$stress in CCRI41 (a $\mathrm{K}^{+}$inefficient cotton variety) self-grafts (CCRI41/CCRI41, scion/rootstock) and its reciprocal grafts (SCRC22/CCRI41) with SCRC22 (a K+ efficient variety); while genes within the white box represent the components involved in feedback regulation of $\mathrm{K}^{+}$uptake and root growth under $\mathrm{K}^{+}$deficiency, they were specifically identified in the roots of SCRC22/CCRI41 or oppositely regulated by low $\mathrm{K}^{+}$in CCRI41/CCRI41 and SCRC22/CCRI41. The red and blue highlighted genes were up- and down-regulated by low $\mathrm{K}^{+}$respectively. 
Supplementary Materials: The following are available online at https: / /www.mdpi.com/1422-006 $7 / 22 / 6 / 3133 /$ s1.

Author Contributions: X.T. and Z.L. designed and conceived the experiments. D.Y. carried out the experiments, analyzed and interpreted the data. D.Y. and X.T. prepared the manuscript. F.L. and F.Y. conceived the study and participated in its design. A.E.E. revised the manuscript. All authors have read and agreed to the published version of the manuscript.

Funding: This work was supported by the Genetically Modified Organisms Breeding Major Projects of China Grant (2016ZX08005-004 to X.T.).

Acknowledgments: We thank graduate student Zhaobin Ren at China Agricultural University for help in processing data. We thank graduate students Yuxian Wang and Xianyuan Gao at China Agricultural University for help in performing the experiments.

Conflicts of Interest: The authors declare no conflict of interest.

\section{References}

1. Ahanger, M.A.; Tittal, M.; Mir, R.A.; Agarwal, R.M. Alleviation of water and osmotic stress-induced changes in nitrogen metabolizing enzymes in Triticum aestivum L. cultivars by potassium. Protoplasma 2017, 254, 1953-1963. [CrossRef] [PubMed]

2. Maathuis, F.J.M. Physiological functions of mineral macronutrients. Curr. Opin. Plant Biol. 2009, 12, 250-258. [CrossRef] [PubMed]

3. Pettigrew, W.T. Potassium influences on yield and quality production for maize, wheat, soybean and cotton. Physiol. Plant. 2008, 133, 670-681. [CrossRef] [PubMed]

4. Wang, Y.; Chen, Y.F.; Wu, W.H. Potassium and phosphorus transport and signaling in plants. J. Integr. Plant Biol. $2020,63,34-52$. [CrossRef] [PubMed]

5. Wang, Y.; Wu, W.H. Potassium transport and signaling in higher plants. Annu. Rev. Plant Biol. 2013, 64, 451-476. [CrossRef]

6. Wang, Y.; Wu, W.H. Regulation of potassium transport and signaling in plants. Curr. Opin. Plant Biol. 2017, 39, 123-128. [CrossRef]

7. de Bang, T.C.; Husted, S.; Laursen, K.H.; Persson, D.P.; Schjoerring, J.K. The molecular-physiological functions of mineral macronutrients and their consequences for deficiency symptoms in plants. New Phytol. 2020, 229, 5.

8. Seybold, H.; Trempel, F.; Scheel, R.; Dierk, S.; Romeis, T.; Lee, J. Ca ${ }^{2+}$ signalling in plant immune response: From pattern recognition receptors to $\mathrm{Ca}^{2+}$ decoding mechanisms. New Phytol. 2014, 204, 782-790. [CrossRef]

9. Steinhorst, L.; Kudla, J. Calcium and reactive oxygen species rule the waves of signaling. Plant Physiol. 2013, 163, 471-485. [CrossRef]

10. Schulz, P.; Romeis, H.T. Calcium-Dependent Protein Kinases: Hubs in Plant Stress Signaling and Development. Plant Physiol. 2013, 163, 523-530. [CrossRef]

11. Srivastava, A.K.; Shankar, A.; Nalini Chandran, A.K.; Sharma, M.; Jung, K.H.; Suprasanna, P.; Pandey, G.K. Emerging concepts of potassium homeostasis in plants. J. Exp. Bot. 2020, 71, 608-619. [CrossRef] [PubMed]

12. Lan, W.; Lee, S.; Che, Y.; Jiang, Y.; Luan, S. Mechanistic analysis of AKT1 regulation by the CBL-CIPK-PP2CA interactions. Mol. Plant 2011, 4, 527-536. [CrossRef]

13. Ragel, P.; Rodenas, R.; Garcia-Martin, E.; Andres, Z.; Villalta, I.; Nieves-Cordones, M.; Rivero, R.M.; Martinez, V.; Pardo, J.M.; Quintero, F.J.; et al. The CBL-Interacting Protein Kinase CIPK23 Regulates HAK5-Mediated High-Affinity K ${ }^{+}$Uptake in $^{-}$ Arabidopsis Roots. Plant Physiol. 2015, 169, 2863-2873. [PubMed]

14. Gajdanowicz, P.; Michard, E.; Sandmann, M.; Rocha, M.; Correa, L. Potassium $\left(\mathrm{K}^{+}\right)$gradients serve as a mobile energy source in plant vascular tissues. Proc. Natl. Acad. Sci. USA 2011, 108, 864-869. [CrossRef] [PubMed]

15. Held, K.; Pascaud, F.; Eckert, C.; Gajdanowicz, P.; Hashimoto, K.; Corratgé-Faillie, C.; Offenborn, J.N.; Lacombe, B.; Dreyer, I.; Thibaud, J.-B.; et al. Calcium-dependent modulation and plasma membrane targeting of the AKT2 potassium channel by the CBL4/CIPK6 calcium sensor/protein kinase complex. Cell Res. 2011, 21, 1116-1130. [CrossRef]

16. Chen, Q.H.; Yang, G.W. Signal Function Studies of ROS, Especially RBOH-Dependent ROS, in Plant Growth, Development and Environmental Stress. J. Plant Growth Regul. 2019, 39, 157-171. [CrossRef]

17. An, J.; Hu, P.G.; Li, F.J.; Wu, H.H.; Shen, Y.; White, J.C.; Tian, X.L.; Li, Z.H.; Giraldo, J.P. Emerging investigator series: Molecular mechanisms of plant salinity stress tolerance improvement by seed priming with cerium oxide nanoparticles. Environ. Sci. Nano 2020, 7, 2214-2228. [CrossRef]

18. Gupta, D.K.; Palma, J.M.; Corpas, F.J. Reactive Oxygen Species and Oxidative Damage in Plants Under Stress I I Redox Regulation and Antioxidant Defence During Abiotic Stress: What Have We Learned from Arabidopsis and Its Relatives; Springer: Berlin/Heidelberg, Germany, 2015; pp. 83-113.

19. Zhang, Z.Y.; Wang, Q.L.; Li, Z.H.; Duan, L.S.; Tian, X.L. Effect of Potassium Deficiency on Root Growth of Cotton (Gossypium hirsutum L.) Seedlings and Its Physiological Mechanisms Involved. Acta Agron. Sin. 2009, 35, 718-723. [CrossRef]

20. Sustr, M.; Soukup, A.; Tylova, E. Potassium in Root Growth and Development. Plants 2019, 8, 435. [CrossRef] [PubMed]

21. Osakabe, Y.; Arinaga, N.; Umezawa, T.; Katsura, S.; Nagamachi, K.; Tanaka, H.; Ohiraki, H.; Yamada, K.; Seo, S.U.; Abo, M. Osmotic stress responses and plant growth controlled by potassium transporters in Arabidopsis. Plant Cell 2013, 25, 609-624. [CrossRef] 
22. Rigas, S.; Debrosses, G.; Haralampidis, K.; Vicente-Agullo, F.; Feldmann, K.; Grabov, A.; Dolan, L.; Hatzopoulos, P. TRH1 encodes a potassium transporter required for tip growth in Arabidopsis root hairs. Plant Cell 2001, 13, 139-151. [CrossRef] [PubMed]

23. Vicente-Agullo, F.; Rigas, S.; Desbrosses, G.; Dolan, L.; Hatzopoulos, P.; Grabov, A. Potassium carrier TRH1 is required for auxin transport in Arabidopsis roots. Plant J. Cell Mol. Biol. 2004, 40, 523-535. [CrossRef]

24. Nam, Y.J.; Tran, L.S.; Kojima, M.; Sakakibara, H.; Nishiyama, R.; Shin, R. Regulatory roles of cytokinins and cytokinin signaling in response to potassium deficiency in Arabidopsis. PLoS ONE 2012, 7, e47797. [CrossRef] [PubMed]

25. Li, G.Z.; Wu, Y.F.; Liu, G.Y.; Xiao, X.H.; Wang, P.F.; Gao, T.; Xu, M.J.; Han, Q.X.; Wang, Y.H.; Guo, T.C.; et al. Large-scale Proteomics Combined with Transgenic Experiments Demonstrates An Important Role of Jasmonic Acid in Potassium Deficiency Response in Wheat and Rice. Mol. Cell Proteom. 2017, 16, 1889-1905. [CrossRef] [PubMed]

26. Li, L.G.; Kim, B.G.; Cheong, Y.H.; Pandey, G.K.; Luan, S. A Ca ${ }^{2+}$ signaling pathway regulates a $\mathrm{K}^{+}$channel for low-K response in Arabidopsis. Proc. Natl. Acad. Sci. USA 2006, 103, 12625-12630. [CrossRef]

27. Xu, J.; Li, H.D.; Chen, L.Q.; Wang, Y.; Liu, L.L.; He, L.; Wu, W.H. A Protein Kinase, Interacting with Two Calcineurin B-like Proteins, Regulates K+ Transporter AKT1 in Arabidopsis. Cell 2006, 125, 1347-1360. [CrossRef]

28. Lee, S.C.; Lan, W.Z.; Kim, B.G.; Li, L.; Cheong, Y.H.; Pandey, G.K. A protein phosphorylation/dephosphorylation network regulates a plant potassium channel. Proc. Natl. Acad. Sci. USA 2007, 104, 15959-15964. [CrossRef] [PubMed]

29. Jung, J.Y.; Shin, R.; Schachtman, D.P. Ethylene mediates response and tolerance to potassium deprivation in Arabidopsis. Plant Cell 2009, 21, 607-621. [CrossRef]

30. Ahn, S.; Shin, R.; Schachtman, D. Expression of KT/KUP genes in Arabidopsis and the role of root hairs in $\mathrm{K}^{+}$uptake. Plant Physiol. 2004, 134, 1135-1145. [CrossRef]

31. Armengaud, P.; Breitling, R.; Amtmann, A. The potassium-dependent transcriptome of Arabidopsis reveals a prominent role of jasmonic acid in nutrient signaling. Plant Physiol. 2004, 136, 2556-2576. [CrossRef]

32. Takehisa, H.; Sato, Y.; Antonio, B.A.; Nagamura, Y. Global transcriptome profile of rice root in response to essential macronutrient deficiency. Plant Signal. Behav. 2014, 8, e24409. [CrossRef] [PubMed]

33. Armengaud, P.; Breitling, R.; Amtmann, A. Coronatine-Insensitive 1 (COI1) Mediates Transcriptional Responses of Arabidopsis thaliana to External Potassium Supply. Mol. Plant 2010, 3, 390-405. [CrossRef] [PubMed]

34. Ma, T.L.; Wu, W.H.; Wang, Y. Transcriptome analysis of rice root responses to potassium deficiency. BMC Plant Biol. 2012, $12,161$. [CrossRef] [PubMed]

35. Zeng, J.B.; He, X.Y.; Wu, D.Z.; Zhu, B.; Cai, S.G.; Nadira, U.A.; Jabeen, Z.; Zhang, G. Comparative Transcriptome Profiling of Two Tibetan Wild Barley Genotypes in Responses to Low Potassium. PLoS ONE 2014, 9, e100567. [CrossRef]

36. Fan, M.L.; Huang, Y.; Zhong, Y.Q.; Kong, Q.S.; Xie, J.J.; Niu, M.L.; Xu, Y.; Bie, Z.L. Comparative transcriptome profiling of potassium starvation responsiveness in two contrasting watermelon genotypes. Planta 2013, 239, 397-410. [CrossRef] [PubMed]

37. Yang, H.; Li, Y.; Jin, Y.M.; Kan, L.P.; Dong, C.X. Transcriptome Analysis of Pyrus betulaefolia Seedling Root Responses to Short-Term Potassium Deficiency. Int. J. Mol. Sci. 2020, 21, 8857. [CrossRef]

38. Gierth, M.; Maser, P.; Schroeder, J.I. The potassium transporter AtHAK5 functions in $\mathrm{K}^{+}$deprivation-induced high-affinity $\mathrm{K}^{+}$ uptake and $A K T 1 \mathrm{~K}^{+}$channel contribution to $\mathrm{K}^{+}$uptake kinetics in Arabidopsis roots. Plant Physiol. 2005, 137, 1105-1114. [CrossRef]

39. Martinez-Cordero, M.A. High-affinity $\mathrm{K}^{+}$uptake in pepper plants. J. Exp. Bot. 2005, 56, 1553-1562. [CrossRef]

40. Nieves-Cordones, M.; Martínez-Cordero, M.A.; Martínez, V.; Rubio, F. An NH4 ${ }^{+}$-sensitive component dominates high-affinity K ${ }^{+}$ uptake in tomato plants. Plant Sci. 2007, 172, 273-280. [CrossRef]

41. Wang, Y.; Wang, Y.; Li, B.; Xiong, C.; Eneji, A.E.; Zhang, M.; Li, F.; Tian, X.; Li, Z. The Cotton High-Affinity K ${ }^{+}$Transporter, GhHAK5a, Is Essential for Shoot Regulation of $\mathrm{K}^{+}$Uptake in Root under Potassium Deficiency. Plant Cell Physiol. 2019, 60, 888-899. [CrossRef]

42. Kim, M.J.; Ruzicka, D.; Shin, R.; Schachtman, D.P. The Arabidopsis AP2/ERF transcription factor RAP2.11 modulates plant response to low-potassium conditions. Mol. Plant 2012, 5, 1042-1057. [CrossRef]

43. Zhao, S.; Zhang, M.L.; Ma, T.L.; Wang, Y. Phosphorylation of ARF2 Relieves Its Repression of Transcription of the $\mathrm{K}^{+}$Transporter Gene HAK5 in Response to Low Potassium Stress. Plant Cell 2016, 28, 3005-3019. [CrossRef]

44. Zhang, Z.Y.; Chao, M.N.; Wang, S.F.; Bu, J.J.; Tang, J.X.; Li, F.; Wang, Q.L.; Zhang, B.H. Proteome quantification of cotton xylem sap suggests the mechanisms of potassium-deficiency-induced changes in plant resistance to environmental stresses. Sci. Rep. 2016, 6, 21060. [CrossRef]

45. Zeng, J.B.; Quan, X.Y.; He, X.Y.; Cai, S.G.; Ye, Z.L.; Chen, G.; Zhang, G.P. Root and leaf metabolite profiles analysis reveals the adaptive strategies to low potassium stress in barley. BMC Plant Biol. 2018, 18, 187. [CrossRef] [PubMed]

46. Li, L.Q.; Lyu, C.C.; Huang, L.P.; Chen, Q.; Zhuo, W.; Wang, X.Y.; Lu, Y.F.; Zeng, F.C.; Lu, L.M. Physiology and proteomic analysis reveals root, stem and leaf responses to potassium deficiency stress in alligator weed. Sci. Rep. 2019, 9, 17366. [CrossRef] [PubMed]

47. He, Y.D.; Li, R.M.; Lin, F.; Xiong, Y.; Wang, L.X.; Wang, B.Z.; Guo, J.C.; Hu, C.X. Transcriptome Changes Induced by Different Potassium Levels in Banana Roots. Plants 2019, 9, 11. [CrossRef] [PubMed]

48. Zhang, T.; Hu, Y.; Jiang, W.; Fang, L.; Guan, X.; Chen, J.; Zhang, J.; Saski, C.A.; Scheffler, B.E.; Stelly, D.M.; et al. Sequencing of allotetraploid cotton (Gossypium hirsutum L. acc. TM-1) provides a resource for fiber improvement. Nat. Biotechnol. 2015, 33, 531-537. [CrossRef] 
49. Véry, A.; Nieves-Cordones, M.; Daly, M.; Khan, I.; Fizames, C.; Sentenac, H. Molecular biology of $\mathrm{K}^{+}$transport across the plant cell membrane: What do we learn from comparison between plant species? J. Plant Physiol. 2014, 171, 748-769. [CrossRef] [PubMed]

50. Forieri, I.; Sticht, C.; Reichelt, M.; Gretz, N.; Hawkesford, M.J.; Malagoli, M.; Wirtz, M.; Hell, R. System analysis of metabolism and the transcriptome in Arabidopsis thaliana roots reveals differential co-regulation upon iron, sulfur and potassium deficiency. Plant Cell Environ. 2017, 40, 95-107. [CrossRef] [PubMed]

51. Xu, Y.C.; Magwanga, R.O.; Yang, X.; Jin, D.S.; Cai, X.Y.; Hou, Y.Q.; Wei, Y.Y.; Zhou, Z.L.; Wang, K.B.; Liu, F. Genetic regulatory networks for salt-alkali stress in Gossypium hirsutum with differing morphological characteristics. BMC Genom. 2020, 21, 15. [CrossRef]

52. Yuan, Y.; Xing, H.; Zeng, W.; Xu, J.; Mao, L.; Wang, L.; Feng, W.; Tao, J.; Wang, H.; Zhang, H.; et al. Genome-wide association and differential expression analysis of salt tolerance in Gossypium hirsutum L at the germination stage. BMC Plant Biol. 2019, 19, 394. [CrossRef]

53. Han, M.G.; Lu, X.K.; Yu, J.; Chen, X.G.; Wang, X.G.; Malik, W.; Wang, J.J.; Wang, D.L.; Wang, S.; Guo, L.X.; et al. Transcriptome Analysis Reveals Cotton (Gossypium hirsutum) Genes That Are Differentially Expressed in Cadmium Stress Tolerance. Int. J. Mol. Sci. 2019, 20, 1479. [CrossRef] [PubMed]

54. Rudd, J.J.; Franklin-Tong, V.E. Unravelling response-specificity in $\mathrm{Ca}^{2+}$ signalling pathways in plant cells. New Phytol. 2010, 151, 7-33. [CrossRef]

55. Shin, R.; Schachtman, D. Hydrogen peroxide mediates plant root cell response to nutrient deprivation. Proc. Natl. Acad. Sci. USA 2004, 101, 8827-8832. [CrossRef] [PubMed]

56. Schachtman, D.P. The Role of Ethylene in Plant Responses to $\mathrm{K}^{+}$Deficiency. Front. Plant Sci. 2015, 6, 1153. [CrossRef] [PubMed]

57. Huang, Y.; Cao, H.S.; Yang, L.; Chen, C.; Shabala, L.; Xiong, M.; Niu, M.L.; Liu, J.; Zheng, Z.H.; Zhou, L.J.; et al. Tissue-specific respiratory burst oxidase homolog-dependent $\mathrm{H}_{2} \mathrm{O}_{2}$ signaling to the plasma membrane $\mathrm{H}^{+}$-ATPase confers potassium uptake and salinity tolerance in Cucurbitaceae. J. Exp. Bot. 2019, 70, 5879-5893. [CrossRef] [PubMed]

58. Demidchik, V.; Maathuis, F.; Voitsekhovskaja, O. Unravelling the plant signalling machinery: An update on the cellular and genetic basis of plant signal transduction. Funct. Plant Biol. 2018, 45, 1-8. [CrossRef]

59. Zhao, X.M.; Liu, Y.; Liu, X.; Jiang, J. Comparative Transcriptome Profiling of Two Tomato Genotypes in Response to PotassiumDeficiency Stress. Int. J. Mol. Sci. 2018, 19, 2402. [CrossRef] [PubMed]

60. Liu, C.K.; Tu, B.J.; Wang, X.; Li, Y.S.; Zhang, Q.Y.; Liu, X.B. Transcript Profile in Vegetable Soybean Roots Reveals Potential Gene Patterns Regulating K Uptake Efficiency. Agronomy 2020, 10, 1796. [CrossRef]

61. Zhang, H.; Yu, Z.J.; Yao, X.D.; Chen, J.L.; Jin, Y. Genome-wide identification and characterization of small auxin-up RNA (SAUR) gene family in plants: Evolution and expression profiles during normal growth and stress response. BMC Plant Biol. 2021, 21, 4. [CrossRef]

62. Jeong, J.; Park, S.; Im, J.H.; Yi, H. Genome-wide identification of GH3 genes in Brassica oleracea and identification of a promoter region for anther-specific expression of a GH3 gene. BMC Genom. 2021, 22, 22. [CrossRef] [PubMed]

63. Kirungu, J.N.; Magwanga, R.O.; Lu, P.; Cai, X.Y.; Liu, F. Functional characterization of Gh_A08G1120 (GH3.5) gene reveal their significant role in enhancing drought and salt stress tolerance in cotton. BMC Genet. 2019, 20, 62. [CrossRef] [PubMed]

64. Garcia, K.; Chasman, D.; Roy, S.; Ané, J.M. Physiological Responses and Gene Co-Expression Network of Mycorrhizal Roots under K $\mathrm{K}^{+}$Deprivation. Plant Physiol. 2017, 173, 1811-1823. [CrossRef] [PubMed]

65. Iliev, E.A.; Xu, W.; Polisensky, D.H.; Oh, M.H.; Torisky, R.S.; Clouse, S.D.; Braam, J. Transcriptional and posttranscriptional regulation of Arabidopsis TCH4 expression by diverse stimuli. Roles of cis regions and brassinosteroids. Plant Physiol. 2002, 130, 770-783. [CrossRef] [PubMed]

66. Li, L.Q.; Li, J.; Chen, Y.; Lu, Y.F.; Lu, L.M. De novo transcriptome analysis of tobacco seedlings and identification of the early response gene network under low-potassium stress. Genet. Mol. Res. 2016, 15, 15. [CrossRef]

67. Ruan, L.; Zhang, J.; Xin, X.; Zhang, C.; Ma, D.; Chen, L.; Zhao, B. Comparative analysis of potassium deficiency-responsive transcriptomes in low potassium susceptible and tolerant wheat (Triticum aestivum L.). Sci. Rep. 2015, 5, 10090. [CrossRef]

68. Yang, T.Y.; Feng, H.M.; Zhang, S.; Xiao, H.J.; Hu, Q.D.; Chen, G.; Xuan, W.; Moran, N.; Murphy, A.; Yu, L.; et al. Potassium transporter OsHAK5 alters rice architecture via ATP-dependent transmembrane auxin fluxes. Plant Commun. 2020, $5,100052$. [CrossRef]

69. Zhang, M.; Huang, P.; Ji, Y.; Wang, S.; Wang, S.; Li, Z.; Guo, Y.; Ding, Z.; Wu, W.; Wang, Y. KUP9 maintains root meristem activity by regulating $\mathrm{K}^{+}$and auxin homeostasis in response to low K. Embo Rep. 2020, 21, e50164. [CrossRef]

70. Hu, W.; Di, Q.; Zhang, J.; Liu, J.; Shi, X.J. Response of grafting tobacco to low potassium stress. BMC Plant Biol. 2020, 20, 286. [CrossRef]

71. Du, X.Q.; Wang, F.L.; Li, H.; Jing, S.; Yu, M.; Li, J.; Wu, W.H.; Kudla, J.; Wang, Y. The Transcription Factor MYB59 Regulates $\mathrm{K}^{+} / \mathrm{NO}_{3}{ }^{-}$Translocation in the Arabidopsis Response to Low $\mathrm{K}^{+}$Stress. Plant Cell 2019, 31, 699-714. [CrossRef]

72. Ruffel, S. Nutrient-Related Long-Distance Signals: Common Players and Possible Cross-Talk. Plant Cell Physiol. 2018, 59, 1723-1732. [CrossRef]

73. Li, H.; Yu, M.; Du, X.Q.; Wang, Z.F.; Wu, W.H.; Quintero, F.J.; Jin, X.H.; Li, H.D.; Wang, Y. NRT1.5/NPF7.3 Functions as a Proton-Coupled $\mathrm{H}^{+} / \mathrm{K}^{+}$Antiporter for $\mathrm{K}^{+}$Loading into the Xylem in Arabidopsis. Plant Cell 2017, 29, 2016-2026. [CrossRef] 
74. Bouguyon, E.; Perrine-Walker, F.; Pervent, M.; Rochette, J.; Cuesta, C.; Benkova, E.; Martinière, A.; Bach, L.; Krouk, G.; Gojon, A.; et al. Nitrate Controls Root Development through Posttranscriptional Regulation of the NRT1.1/NPF6.3 Transporter/Sensor. Plant Physiol. 2016, 172, 1237-1248. [PubMed]

75. Balzergue, C.; Dartevelle, T.; Godon, C.; Laugier, E.; Meisrimler, C.; Teulon, J.; Creff, A.; Bissler, M.; Brouchoud, C.; Hagège, A.; et al. Low phosphate activates STOP1-ALMT1 to rapidly inhibit root cell elongation. Nat. Commun. 2017, 8, 15300. [CrossRef] [PubMed]

76. Guo, W.J.; Nagy, R.; Chen, H.Y.; Pfrunder, S.; Yu, Y.C.; Santelia, D.; Frommer, W.B.; Martinoia, E. SWEET17, a facilitative transporter, mediates fructose transport across the tonoplast of Arabidopsis roots and leaves. Plant Physiol. 2014, 164, 777-789. [CrossRef]

77. Chen, H.Y.; Huh, J.H.; Yu, Y.C.; Ho, L.H.; Chen, L.Q.; Tholl, D.; Frommer, W.B.; Guo, W.J. The Arabidopsis vacuolar sugar transporter SWEET2 limits carbon sequestration from roots and restricts Pythium infection. Plant J. Cell Mol. Biol. 2015, 83, 1046-1058. [CrossRef]

78. Pradhan, S.K.; Pandit, E.; Nayak, D.K.; Behera, L.; Mohapatra, T. Genes, pathways and transcription factors involved in seedling stage chilling stress tolerance in indica rice through RNA-Seq analysis. BMC Plant Biol. 2019, 19, 352. [CrossRef] [PubMed]

79. Raddatz, N.; Morales de Los Rios, L.; Lindahl, M.; Quintero, F.J.; Pardo, J.M. Coordinated Transport of Nitrate, Potassium, and Sodium. Front. Plant Sci. 2020, 11, 247. [CrossRef] [PubMed]

80. Zhao, L.; Liu, F.; Crawford, N.; Wang, Y. Molecular Regulation of Nitrate Responses in Plants. Int. J. Mol. Sci. 2018, 19, 2039. [CrossRef]

81. Hong, J.P.; Takeshi, Y.; Kondou, Y.; Schachtman, D.P.; Matsui, M.; Shin, R. Identification and characterization of transcription factors regulating Arabidopsis HAK5. Plant Cell Physiol. 2013, 54, 1478-1490. [CrossRef]

82. Wang, R.; Jing, W.; Xiao, L.Y.; Jin, Y.K.; Shen, L.K.; Zhang, W.H. The Rice High-Affinity Potassium Transporter1;1 Is Involved in Salt Tolerance and Regulated by an MYB-Type Transcription Factor. Plant Physiol. 2015, 168, 1076-1090. [CrossRef]

83. Cao, X.Y.; Hu, L.Q.; Chen, X.Y.; Zhang, R.Z.; Cheng, D.G.; Li, H.S.; Xu, Z.S.; Li, L.C.; Zhou, Y.B.; Liu, A.F.; et al. Genome-wide analysis and identification of the low potassium stress responsive gene SiMYB3 in foxtail millet (Setariaitalica L.). BMC Genom. 2019, 20, 136. [CrossRef] [PubMed]

84. Zhang, X.Q.; Jiang, H.; Wang, H.; Cui, J.; Wang, J.H.; Hu, J.; Guo, L.B.; Qian, Q.; Xue, D.W. Transcriptome Analysis of Rice Seedling Roots in Response to Potassium Deficiency. Sci. Rep. 2017, 7, 5523. [CrossRef]

85. Tu, X.Y.; Mejía-Guerra, M.K.; Valdes Franco, J.A.; Tzeng, D.; Chu, P.Y.; Shen, W.; Wei, Y.Y.; Dai, X.R.; Li, P.H.; Buckler, E.S.; et al. Reconstructing the maize leaf regulatory network using ChIP-seq data of 104 transcription factors. Nat. Commun. 2020, 11, 5089. [CrossRef] [PubMed]

86. Li, B.; Wang, Y.; Zhang, Z.; Wang, B.; Eneji, A.E.; Duan, L.; Li, Z.; Tian, X. Cotton shoot plays a major role in mediating senescence induced by potassium deficiency. J. Plant Physiol. 2012, 169, 327-335. [CrossRef]

87. Tang, D.; Qian, H.; Zhao, L.; Huang, D.; Tang, K. Transgenic tobacco plants expressing BoRS1 gene from Brassica oleracea var. acephala show enhanced tolerance to water stress. J. Biosci. 2005, 30, 647-655. [PubMed]

88. Xu, J.; Tian, X.L.; Egrinya, E.A.; Li, Z.H. Functional characterization of GhAKT1, a novel Shaker-like $\mathrm{K}^{+}$channel gene involved in $\mathrm{K}^{+}$uptake from cotton (Gossypium hirsutum). Gene 2014, 545, 61-71. [CrossRef]

89. Siren, J.; Valimaki, N.; Makinen, V. Indexing Graphs for Path Queries with Applications in Genome Research. IEEE/ACM Trans. Comput. Biol. Bioinform. 2014, 11, 375-388. [CrossRef]

90. Mortazavi, A.; Williams, B.A.; McCue, K.; Schaeffer, L.; Wold, B. Mapping and quantifying mammalian transcriptomes by RNA-Seq. Nat. Methods 2008, 5, 621-628. [CrossRef]

91. Love, M.I.; Huber, W.; Anders, S. Moderated estimation of fold change and dispersion for RNA-seq data with DESeq2. Genome Biol. 2014, 15, 550. [CrossRef]

92. Kanehisa, M.; Araki, M.; Goto, S.; Hattori, M.; Hirakawa, M.; Itoh, M.; Katayama, T.; Kawashima, S.; Okuda, S.; Tokimatsu, T.; et al. KEGG for linking genomes to life and the environment. Nucleic Acids Res. 2008, 36, D480-D484. [CrossRef]

93. Young, M.D.; Wakefield, M.J.; Smyth, G.K.; Oshlack, A. Gene ontology analysis for RNA-seq: Accounting for selection bias. Genome Biol. 2010, 11, R14. [CrossRef] [PubMed]

94. Livak, K.J.; Schmittgen, T.D. Analysis of relative gene expression data using real-time quantitative PCR and the $2^{-\Delta \Delta C T}$ Method. Methods 2001, 25, 402. [CrossRef] [PubMed]

95. Jin, J.; Tian, F.; Yang, D.C.; Meng, Y.Q.; Kong, L.; Luo, J.; Gao, G. PlantTFDB 4.0: Toward a central hub for transcription factors and regulatory interactions in plants. Nucleic Acids Res. 2017, 45, D1040-D1045. [CrossRef] [PubMed] 